Article

\title{
Assessing the Hybridization of an Existing Geothermal Plant by Coupling a CSP System for Increasing Power Generation
}

\author{
Yanara Tranamil-Maripe ${ }^{1,+}$, José M. Cardemil $2, *\left(\mathbb{D}\right.$, Rodrigo Escobar 2,3 (D), Diego Morata ${ }^{4,5}$ (D), \\ and Cristóbal Sarmiento-Laurel ${ }^{6}$ (D)
}

check for

updates

Citation: Tranamil-Maripe, Y.; Cardemil, J.M.; Escobar, R.; Morata, D.; Sarmiento-Laurel, C. Assessing the Hybridization of an Existing Geothermal Plant by Coupling a CSP System for Increasing Power Generation. Energies 2022, 15, 1961. https://doi.org/10.3390/en15061961

Academic Editor: Andrea Baccioli

Received: 30 January 2022

Accepted: 3 March 2022

Published: 8 March 2022

Publisher's Note: MDPI stays neutral with regard to jurisdictional claims in published maps and institutional affiliations.

Copyright: (C) 2022 by the authors. Licensee MDPI, Basel, Switzerland. This article is an open access article distributed under the terms and conditions of the Creative Commons Attribution (CC BY) license (https:// creativecommons.org/licenses/by/ $4.0 /)$.
1 Facultad de Ciencias Físicas y Matemáticas, Universidad de Chile, Santiago 8370456, Chile; ytranamil@minenergia.cl

2 Departamento de Ingeniería Mecánica y Metalúrgica, Pontificia Universidad Católica de Chile, Santiago 7820436, Chile; rescobar@ing.puc.cl

3 Centro del Desierto de Atacama, Pontificia Universidad Católica de Chile, Santiago 7820436, Chile

4 Departamento de Geología, Facultad de Ciencias Físicas y Matemáticas, Universidad de Chile, Santiago 8370456, Chile; dmorata@ing.uchile.cl

5 Centro de Excelencia en Geotermia de los Andes (CEGA), Santiago 8370456, Chile

6 School of Industrial Engineering, Universidad Diego Portales, Santiago 8370191, Chile; cristobal.sarmiento@mail.udp.cl

* Correspondence: jmcardem@uc.cl

† Current address: Departamento de Energías Sostenibles, Ministerio de Energía, Santiago 8340518, Chile.

\begin{abstract}
Concentrated Solar Power (CSP) and geothermal energy systems are outlined as two of the most promising technologies for sustainable and reliable electricity generation. Several studies in the technical literature have pointed out that the hybridization of solar and geothermal energy sources could lead to a reduction of the levelized cost of energy (LCOE) of geothermal systems, as well as improving the capacity factor of CSP systems. However, the technical literature shows that the integration of solar thermal collectors does not present a positive impact in all scenarios analyzed. The present study aims to further analyze the competitiveness of the hybridization of solar and geothermal systems under high irradiation conditions such as those observed in the Andean region in northern Chile. The evaluation was carried out by coupling a thermodynamic model in Engineering Equation Solver (EES) with a solar thermal model in the System Advisor Model (SAM). The assessment considers the configuration of an existing geothermal plant, considering the design constraints associated with the actual operating conditions of the plant. The analysis is based on an energy and exergy assessment, allowing us to identify the efficiency of the subsystems introduced for the hybridization and assess the competitiveness of the hybrid schemes by an economic assessment in terms of the LCOE. The results show that the hybrid schemes allow a reduction of the LCOE of a geothermal stand-alone plant by about $10 \mathrm{USD} / \mathrm{MWh}$, increasing the competitiveness of the geothermal system. However, a large variation on such a reduction is observed depending on the size of the solar field and the storage tank of the solar system.
\end{abstract}

Keywords: geothermal plant; binary cycle; Concentrating Solar Energy; thermodynamic analysis; LCOE

\section{Introduction}

According to the last global status report, the share of fossil fuels consumption reaches $80.2 \%$ of the global energy demand, whereas the share of renewable energy sources is only $11.2 \%$. Despite the significant efforts made in recent years for enhancing the utilization of sustainable energy sources, the share of fossil fuels exhibits a positive variation of $0.12 \%$ between 2009 and 2019. That constitutes a nominal stagnation regarding the participation of renewable sources for supplying the world's constantly growing energy demand. In this context, concentrated solar power (CSP) and geothermal energy sources are outlined 
as two of the most promising technologies for sustainable and reliable electricity generation [1]. Both, CSP and geothermal systems, are able to deliver thermal energy for driving conventional energy conversion systems or Organic Rankine cycles (ORC). Indeed, several authors have reported the compatibility between both energy sources, pointing out that hybrid Solar-Geothermal configurations can improve significantly the levelized cost of energy (LCOE) and capacity factor than stand-alone CSP or geothermal systems [2,3]. The low-capacity factor of CSP systems, due to the variation of the solar resource during the day, may be improved by the geothermal constant energy supply. In addition to that, CSP systems exhibit operating temperatures close to $650^{\circ} \mathrm{C}$ [4] that can increase significantly the low conversion efficiencies observed in geothermal applications. The efficiency improvements stated in the literature range between $2.37 \%$ and $81.13 \%$ of increment in hybrid Rankine cycles, and increments from $5.5 \%$ to $81 \%$ in ORC [3]. In addition to that, the availability of solar thermal energy throughout the day reduces the geothermal fluid extraction, decreasing the depletion rate of the geothermal wells, and as a consequence, the operation and maintenance (O\&M) costs [5]. Moreover, the geothermal well may be used as thermal energy storage (TES) for the solar heat produced during energy oversupply intervals [3]. In terms of $\mathrm{CO}_{2}$ emissions, some the geothermal based power systems show a rate of emission under $500 \mathrm{~g}$ of $\mathrm{CO}_{2}$ per $\mathrm{kWh}$, which is the lowest range of emission index in comparison to Hydro-power, solar photovoltaic and fossil sources [6].

Despite the aforementioned advantages of integrating Solar-Geothermal systems, there are still important challenges to be addressed for being considered a reliable solution for the industry. For instance, coupling both energy sources implies a significant increase in the complexity of the power system, and as a consequence, hampering the maintenance and challenging the control strategy during its operation. In addition, the initial costs related to the characterization of the geothermal resource, the installation of the CSP, and geothermal plants are excessively high, hindering the competitiveness of hybrid projects in the short-term $[2,7]$.

Aiming to outperform solar and geothermal power plants as standalone systems, several studies have analyzed the performance of integrating both renewable sources in a hybrid Solar-Geothermal power system, considering their limitations and advantages. Lentz [8] modelled two integration strategies for the hybridization of parabolic trough collectors (PTC) at the Cerro Prieto geothermal power plant in northern Mexico. The study analyzed the benefits of integrating solar heat from a PTC solar field in an existing geothermal power plant. The analysis considered two configurations: (a) preheating the geothermal fluid before the separator to increase the the steam quality, and (b) heating the brine downstream the separator for a second steam extraction at low pressure. The results showed that both integration strategies raise the electricity production in similar rates, however, the silica deposition could be significant if the brine presents high concentration before the first separator. Later, the same authors proposed an actualization of the previous work attending the silica precipitation risk [9]. The authors recommend to include an electronic descaler and the injection of hydrolic acid ( $\mathrm{pH} 5)$, also, they studied a third hybrid configuration. The approach consist in using the solar field to heat the brine flow from the cooling tower to produce steam, and return the mixture of steam and brine to the brine flow coming from the geothermal wells. This configuration allowed to increase the steam generation rate and to control the silica precipitation risk. Handal2007-wh [10] and Alvarenga2008-rr [11] tested a prototype of a PTC solar field deployed to generate additional steam in a geothermal plant. The system considered a cyclonic separator that extracts medium pressure steam from the two-phase mixture coming from a geothermal well. In addition, the solar system heats the remaining brine stream before it is directed to a second flash separator. Thus, the additional solar heat allows to increase the quality of low pressure steam extraction. The authors concluded that the system is technically feasible at large-scale if a commercial solar field can ensure efficiencies over $50 \%$ with an annual capacity factor around 30\%. Greenhut2009-tw [12] analyzed the hybridization of a geothermal plant by integrating a solar system to heat the low enthalpy geothermal fluid. 
The authors reported that the LCOE of the solar system and the geothermal stand-alone plant are similar if the cost of the geothermal well are included. The results show that the electricity generation in the hybrid configuration could be increased, and even double the geothermal generation as a standalone plant. It was also conclude that the unit capacity cost of the plant increases in $100 \mathrm{USD} / \mathrm{kW}$ per every percent of additional solar heat from the total heat input. In a further study considering the same system Greenhut2010 [13] estimated the LCOE in a range of 190 and 250 USD/MWh.

Astolfi2011-nc [14] analyzed the economic feasibility of a hybrid solar geothermal plant deployed in four locations: Pisa, and Palermo in Italy, and San Diego and Imperial in USA. The proposed cycle considers a PTC solar field coupled to a geothermal field to drive a binary transcritical ORC. The results reported LCOE values in a range of 145 to 280 EUR/MWh, allowing to identify Imperial as the location showing the lowest LCOE among the locations analyzed, with a yearly incident solar energy of $2.64 \mathrm{MWh}$. Boghossian2011-dw [15] analyzed the economic feasibility of an hybrid solar-geothermal Kalina power cycle. The analysis considered a variation on the percent relation between the solar and geothermal input to generate $9.5 \mathrm{MW}$ as the cycle output. In that study no synergies were found between the solar geothermal systems. In fact, the author pointed out that the hybrid plant delivers $29 \%$ less power than the solar and geothermal systems in stand-alone configurations. A different thermodynamic and economic analysis of a hybrid solar-geothermal plant was conducted by Manente2012-nx [16]. The authors studied two operation strategies in order to maximize the power output of a subcritical isobutane ORC driven by solar and geothermal sources. The analysis was carried out considering transient environmental conditions, featured by a typical meteorological year database. The first strategy analyzed consist in separate the geothermal heat input in equivalent parts for two expander-generators. The second strategy considers a relation of $33.38-66.62 \%$, to split the mass flow from the steam generator to each expander-generator. The authors recommended to not deploy such systems in regions with relatively low solar resource, since the LCOE of the hybrid ranges between 182 to 191 USD/MWh, higher than the costs of a geothermal stand-alone plant. In 2011, Zhou2011-lx [17] studied the yield of two hybrid solar-geothermal concepts based on ORC, in order to asses the effects of diurnal temperature changes on the performance of air-cooled condensers. The first concept (A) considers a solar system to heat directly the ORC HTF without disregarding the use of a TES. The second concept (B) includes an indirect heating solar system with a synthetic-oil TES to supply thermal energy to the ORC. The authors reported that the system (A) presents better performance in terms of the net power generation and thermal efficiency. The study showed that the hybridization could achieve a stable performance and increase the electric power generation in about of $29 \%$, and an additional $16.6 \%$ in the overall system's thermal efficiency during peak hours. Later, in 2013, Zhou2013-np [18] studied a subcritical regenerative ORC driven by an hybrid solar geothermal scheme. The solar field considers a TES and supply heat to superheat the steam from the geothermal steam generator. The results stated a net exergy efficiency of $12.36 \%$ for the hybrid plant, and LCOE values in a range of 165 to 222 USD/MWh (depending on the solar field size and geothermal well conditions). Zhou2014-pv [19] analyzed a hybrid solar-geothermal plant coupled to a supercritical ORC, and compared its performance with a subcritical ORC and stand-alone solar and geothermal plants. The results show an outperformance in the supercritical ORC when $66 \%$ of energy is supplied by the solar system, increasing the exergy efficiency in a range of $2-4 \%$ over the subcritical ORC configuration. in addition, the authors reported LCOE values between 105 to 160 USD/MWh for the supercritical cycle, and values between 101 to 165 USD/MWh for the subcritical cycle.

In 2014, Ghasemi2014-lc [20] examined the hybridization of an existing ORC utilizing a low-temperature geothermal source coupled to a PTC solar field to enhance the vaporization of the the working fluid in the ORC. The study shows that the hybridization offers better thermodynamic performance in comparison to geothermal stand-alone plants, reaching a $5.5 \%$ boost in annual power generation and an increment of $3.4 \%$ in terms of 
the exergy efficiency. Based in the previous system, Ayub2015-sp [21] analyzed an ORC driven by a low-temperature geothermal well and a solar trough system, to maximize the net power output in representative days. The authors concluded that a hybrid solargeothermal could reach efficiencies between 5.5-6.3\% higher than a geothermal stand-alone systems. However, in terms of the LCOE, geothermal stand alone plants show lower values (60.55 USD/MWh) than the hybrid solar-geothermal scheme (64.73 USD/MWh). This result is explained mainly by the high costs of deploying the solar system. In 2016, a thermoeconomic analysis was performed by Calise2016-ye [22] to assess a hybrid solargeothermal polygeneration plant. The proposed system aims to produce fresh water, electricity, and thermal and cooling energy for a small community located in southern of Italy. The results report a LCOE in the range of 175.2 to $204.5 \mathrm{USD} / \mathrm{MWh}$, to produce chill water between 221.2 to $224.2 \mathrm{USD} / \mathrm{MWh}$, and hot water for space heating of 19.2 to 20.2 USD/MWh. The same year, Cardemil2016-jr [5] conducted a thermodynamic and economic assessment of two hybrid geothermal plants assisted by a PTC solar field. The proposed schemes consist in a single and double flash geothermal systems. The single flash scheme considers the supply of solar heat to superheat the saturated steam coming from the geothermal separator, and to produce additional steam from the geothermal brine outlet from the separator. The double-flash scheme, considers the equivalent processes than the single-flash system, but including an additional solar input to superheat a medium pressure steam from a second separator. The study concludes that both configurations could reduce the mass flow from the geothermal well, and in consequence, it could increase the life time of the geothermal source. In addition to that, the double flash option takes advantage of the first separation brine to exploit its high enthalpy for a second expansion process. The results show an LCOE of $64 \mathrm{USD} / \mathrm{MWh}$ and $56 \mathrm{USD} / \mathrm{MWh}$, for a single and double flash systems, respectively. Jiang2017-qs [23] studied a hybrid solar-geothermal power plant coupled to a supercritical $\mathrm{CO}_{2}$ Brayton cycle. The geothermal reservoir stores pressurized supercritical $\mathrm{CO}_{2}$ heated from a CSP cycle. The geothermal resource provides the base load electricity and solar energy boost the energy generation in daylight hours. The authors stated that the system does not offer advantages for the utilization of the geothermal energy. Nevertheless, the integration simplifies the solar system and reduce the low pressure level of the cycle, helping to conduct $\mathrm{CO}_{2}$ geological sequestration. Bonyadi2018-jp [24] conducted a thermoeconomic and exergy analysis of a solar Rankine cycle hybridized with an existing geothermal power plant based in an ORC. Increases in solar efficiency and decreases in geothermal brine could be reached with the proposal. Also, the results show a LCOE between 163 to 172 USD/MWh. Later, an economic analysis was reported by McTigue2018-mv [25], where five hybridization strategies were analyzed, considering a double flash geothermal plant coupled to a solar field of lineal Fresnel reflectors. The results show an increase on the electricity generation within the range of 22 to $24 \mathrm{MW}$, which presents LCOE values in a range of 70 to $80 \mathrm{USD} / \mathrm{MWh}$ for a plant located in Coso geothermal area, USA.

The first actual solar geothermal hybrid plant is the Stillwater Power Plant, located in Nevada, USA. Stillwater started its operations in 2009 with $26 \mathrm{MW}$ of geothermal power capacity. Two years later, $33 \mathrm{MW}$ of PV capacity was added to the plant. Then, in 2014, 17 MW of PTC were installed to increase its electric capacity in 2 MW. In 2018, Ciani_Bassetti2018-ni [26] analyzed the integration of solar TES in Stillwater, considering two cases: a solar multiple of 1.6, with and without TES system. The results show that the first case increased the electricity generation in 6.3\%, regarding the geothermal plant as stand-alone system, whereas the system without TES showed an increase of $5.3 \%$ in terms of electricity generation.

As described above, the literature review shows that the hybridization of solar and geothermal energy sources has been an active research topic during the last decade. However, the integration of solar thermal collectors does not present a positive impact in all scenarios analyzed in the literature. It has been observed that the best results are observed when the location of the geothermal reservoir is in a region with particularly high solar 
resource, such as in Chile and USA. The present study presents the assessment of the hybridization of an existing geothermal plant, which is located in one of the best locations worldwide, in terms of solar radiation availability. The analysis is based on energy and exergy assessment and considers several design constraints associated with silica precipitation, as well as environmental and cultural constraints since it is located in a protected area. Hence, the analysis presented herein goes one step further on the assessment of solar geothermal systems, by conducting an assessment restricted to actual operating conditions.

\section{System Description}

Cerro Pabellón plant is a geothermal power plant developed by Enel S.A., and in operation since 2017. The power plant is located at 4500 m.a.s.l in a place called Pampa Apacheta in Andean region of the Atacama Dessert (Chile) (21 $51^{\prime} 29.0^{\prime \prime}$ S 68 $09^{\prime} 08.3^{\prime \prime}$ W) [27] (see Figure 1). This power plant is the first and unique geothermal power plant in South America. Pampa Apacheta belongs to a volcanic arc of Andes mountains, whose magma chambers and groundwaters give excellent conditions to exploit hydrothermal systems.

Several explorations have been made around the Pampa Apacheta region to evaluate the geothermal potential for energetic purposes, which were reported in scientific studies and technical reports. In 2014 Procesi2014-vn [28] reported that the temperature of the geothermal fluid could reach $260^{\circ} \mathrm{C}$. Then, according to the environmental impact assessment reported by Geothermics2010-um [29,30], the enthalpy of the geothermal resource at the well-head could drive three different geothermal power technologies: single flash cycle, binary cycle, and a combination of both technologies. In 2017, Cerro Pabellón started to operate with two power modules of binary ORC of $24 \mathrm{MW}$, driven by eleven production wells with depth ranging between 2000 to $2500 \mathrm{~m}$ [30]. One of these modules was selected as the base case for the present study. The binary ORC allows the reinjection of the geothermal fluid at higher temperatures than expected in a flash scheme, allowing to preserve the conditions of the reservoir.

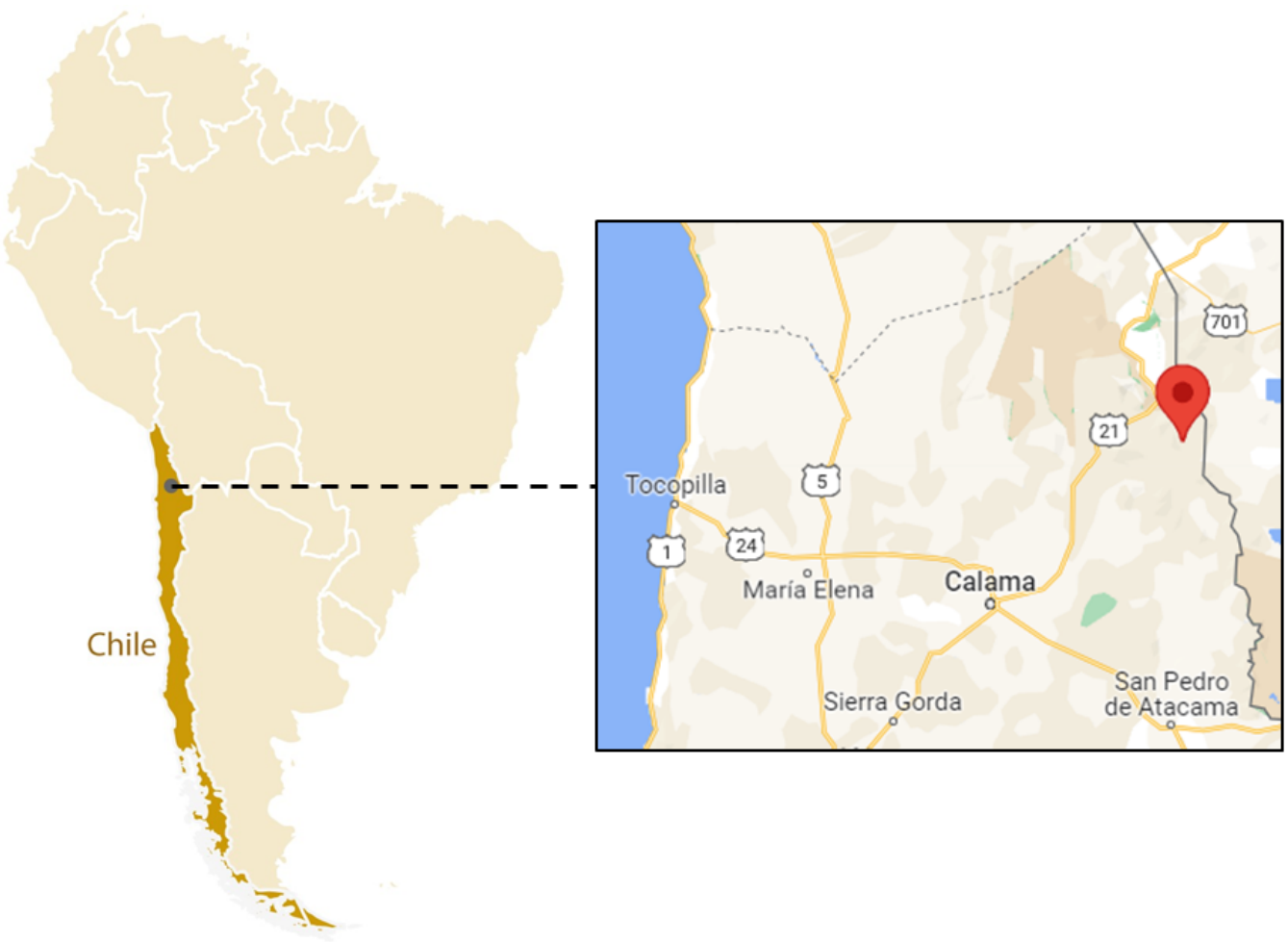

Figure 1. Location of Pampa Apacheta geothermal power plant.

The meteorological conditions in Pampa Apacheta are in general severe, showing a yearly mean thermal amplitude of about $15.0^{\circ} \mathrm{C}$ and a maximum of $24.5^{\circ} \mathrm{C}$, while mean 
ambient temperature varies between $-2{ }^{\circ} \mathrm{C}$ and $3.88^{\circ} \mathrm{C}$ in daylight hours. Regarding to the solar resource, Pampa Apacheta presents a daily mean global horizontal irradiation (GHI) of $7.3 \mathrm{kWh} / \mathrm{m}^{2}$, and a daily direct normal irradiation (DNI) of $9.5 \mathrm{kWh} / \mathrm{m}^{2}$ [31]. Those irradiation levels are among the highest levels in the Chilean territory. The temperature and the irradiation profiles were obtained from the typical meteorological year (TMY) database developed by GeoModel-Solar2019. The temperature and DNI profiles are shown in Figures 2 and 3, respectively.

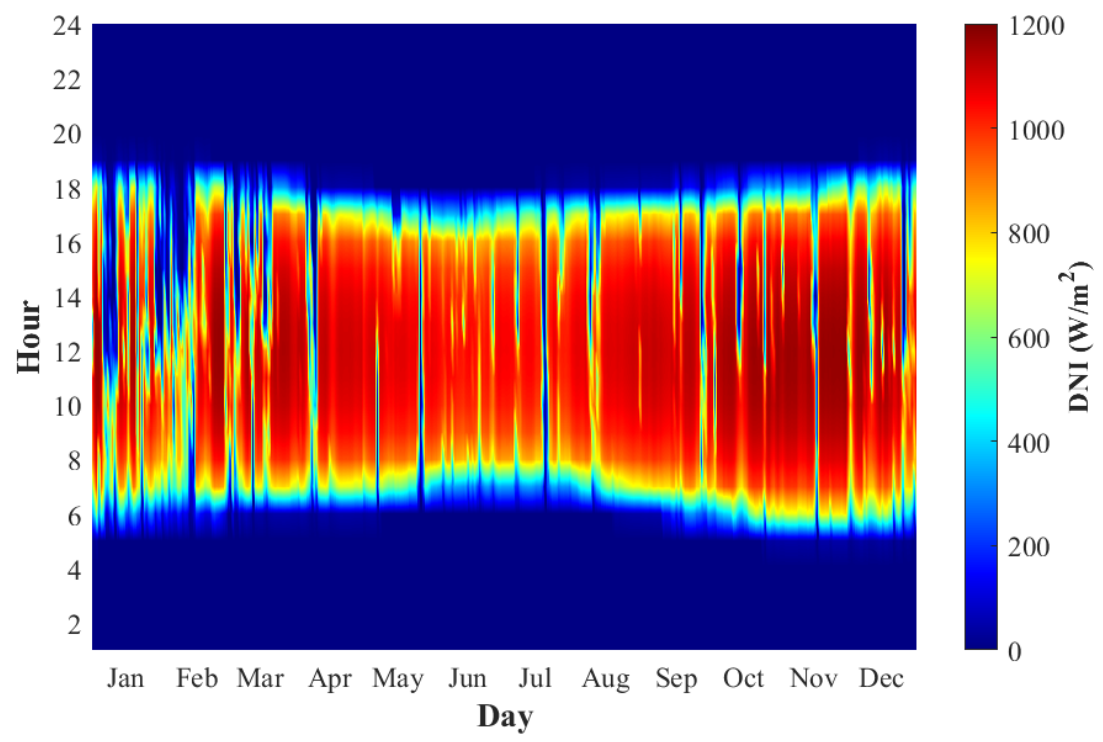

Figure 2. Distribution of the DNI at the Pampa Apacheta site.

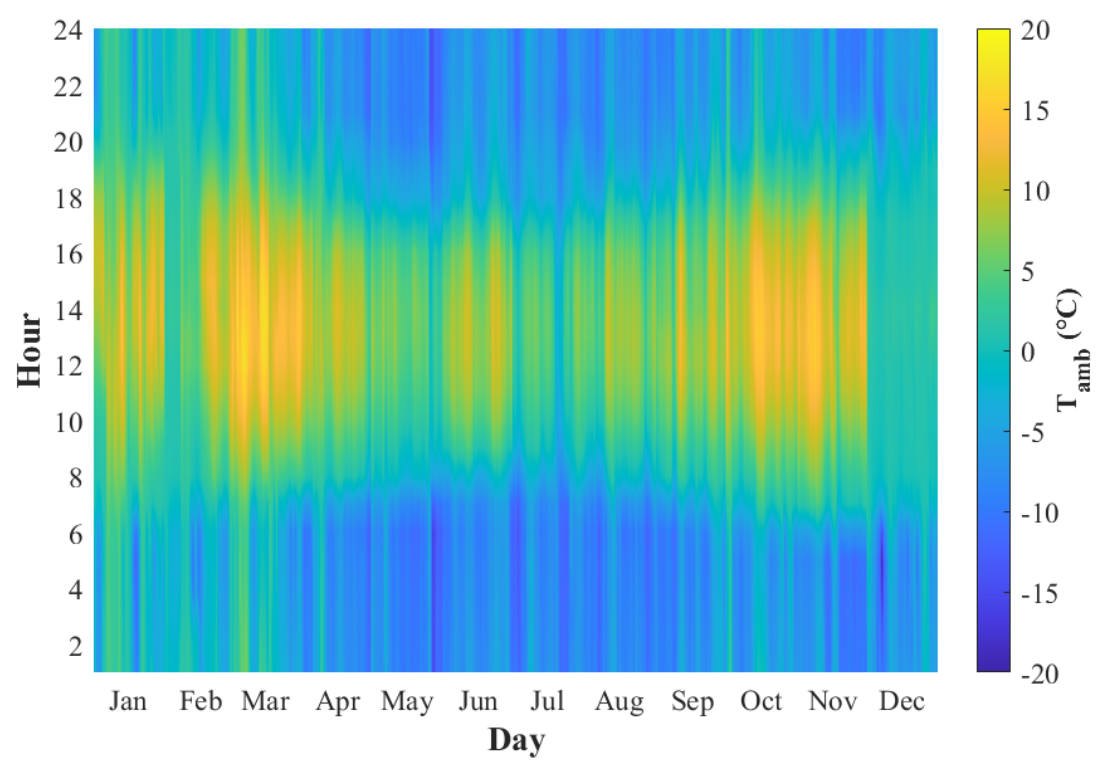

Figure 3. Ambient Temperature at the Pampa Apacheta site.

Some cloudy periods are observed in Figure 2, especially between January and February, reducing DNI and temperature peaks. This seasonal phenomenon is called altiplanic winter, when the high level of atmospheric attenuation decrease, the daily averaged DNI decreases to $8.7 \mathrm{kWh} / \mathrm{m}^{2}$ in January, and $8.4 \mathrm{kWh} / \mathrm{m}^{2}$ in February. On the other hand, on November and December the daily averaged DNI can reach impressive levels as 12.4 and $11.2 \mathrm{~kW} \mathrm{~h} / \mathrm{m}^{2}$, respectively. The high DNI is explained by the clear skies observed during that period of the year, as well as by the high altitude of the location, which reduced the atmospheric attenuation of the solar radiation. 
The present work is focused on the analysis of possible integration schemes for coupling a PTC solar field and the existing geothermal system to increase the electricity production. In this context, two integration schemes were considered for the hybridized solar geothermal plant, using as a starting point the installed binary ORC of $24 \mathrm{MW}$ located at Cerro Pabellón. Finally, to ensure the proper match between both technologies without harming the original configuration and its effects within the reservoir, the environment, and the community, it is imposed as a restriction to keep constant the temperature levels of the $\mathrm{ORC}$, as well as the reinjection temperature of the geothermal fluid. Such constraints bring the additional benefit of avoiding the incrustation and corrosion by silica precipitation in the geothermal system.

\subsection{Base Case}

The binary ORC uses geothermal fluid to preheat and evaporate the organic HTF , which in the case of the present study is isopentane. The diagram of the current geothermal cycle in Cerro Pabellón is shown in Figure 4, where the blue lines represent the geothermal fluid and the green lines the isopentane flowing in the ORC. Due to the high enthalpy levels in the geothermal well, it is possible to observe a two-phase flow from the well in state (WC.2). Hence, the flow goes to a separator (SC101), from where two products are obtained: liquid brine (WC.6), and saturated steam (WC.3). The steam stream goes to a heat exchanger (IC201) to vaporize the isopentane, which goes from the subcooled state in (OC.7) to saturated steam (OC.1). The geothermal steam in the heat exchanger (IC201) is condensed (OC.4), and later pumped (WC.5) and mixed with geothermal brine (WC.7), resulting in the state WC.8. The flow at state (WC.8) preheats the ORC HTF from (OC.6) to (OC.7) in the heat exchanger (IC202). Then, in (IC202), the cooled geothermal fluid output (WC.9) is pumped back to the geothermal reservoir in a reinjection well. The turbine (G201) is driven by saturated steam (OC.1), where the expansion process is carried out, resulting in the expected power output. Once the organic HTF is expanded (OC.2), it is carried towards the (IC203) heat exchanger (acting as a recuperator) which is cooled through an air-cooled condenser (AC201). Finally, the outlet of organic fluid from air-cooled condenser (OC.4) is pumped and preheated in the recuperator, closing the cycle in (OC.6).

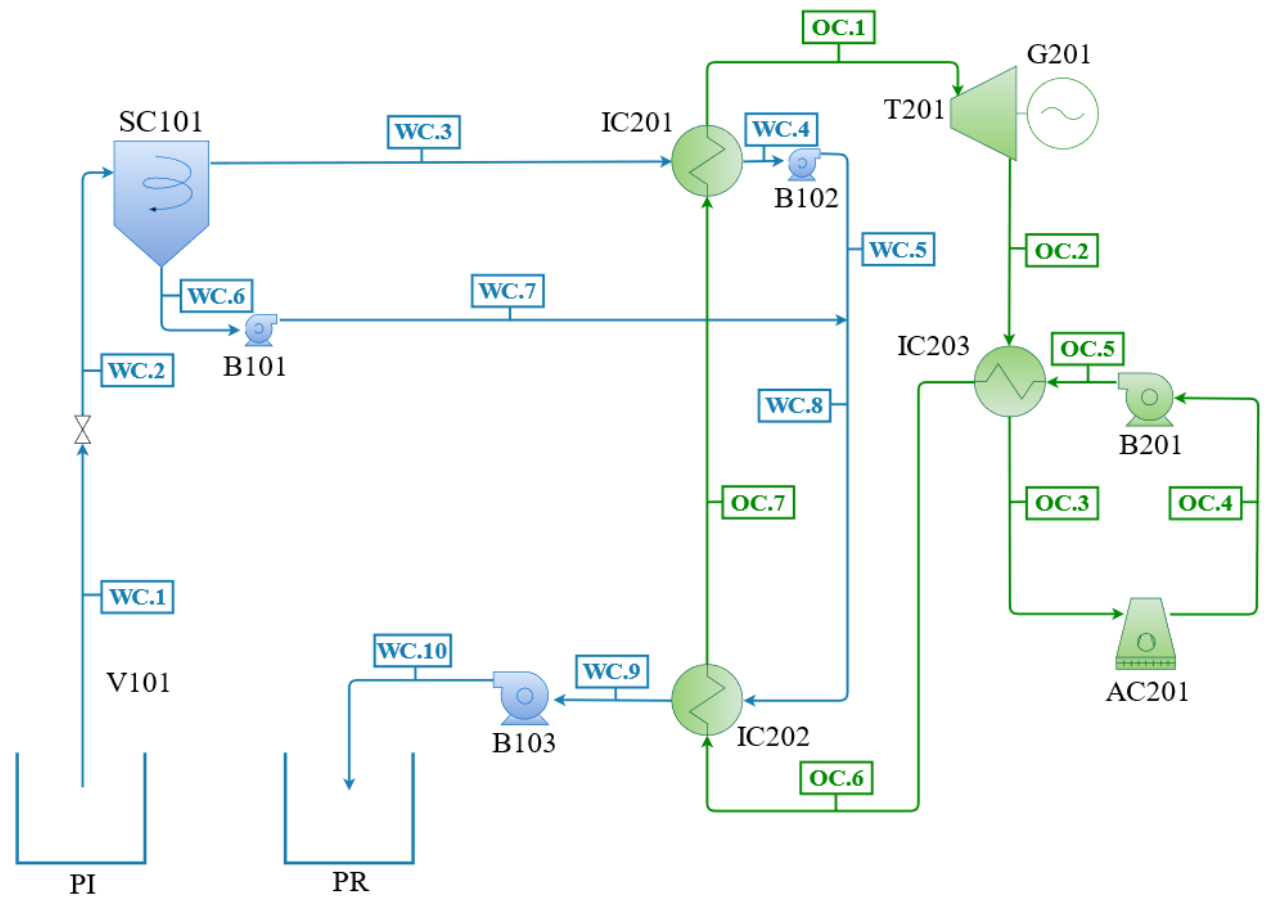

Figure 4. Cerro Pabellón geothermal power plant diagram (Courtesy of Enel Chile S.A). 


\subsection{Hybrid Configurations}

The main objective of hybridizing solar and geothermal resources is to increase the electricity generation by coupling a PTC solar field with the existing binary ORC in Cerro Pabellón geothermal project. To assess the hybridization, four solar thermal capacities were evaluated, 30, 40,50 and 60 MW. Likewise, the analysis ranges the solar multiple and the size of the TES system to find the best configuration for the solar system. The hybrid configurations evaluated are denominated $\mathrm{CHO1}$, which considers a solar field of 30 and $40 \mathrm{MW}$, and, $\mathrm{CH} 02$, which comprehends a solar thermal capacity of 50 and $60 \mathrm{MW}$.

\subsubsection{Hybrid Scheme $\mathrm{CH} 01$}

This configuration considers the inclusion of three additional heat exchangers to transfer heat from the solar field to a new power block. The heat exchangers are denominated (IC101), (IC102), and (IC103), which are employed for preheating, evaporating, and overheating, respectively. In addition, a separator (SC102), a steam turbine (T101), an electric generator (G101), a pump (B104), and an air-cooled condenser (AC101) are also integrated to complete the hybrid scheme. The hybrid configuration $\mathrm{CHO1}$ is depicted in Figure 5, where blue and green lines, as in Figure 4, represent the geothermal and organic fluids, respectively. In addition, two new classes of streams are introduced: red lines indicate the solar heat transfer fluid, and the orange lines represent the streams of the steam power system.

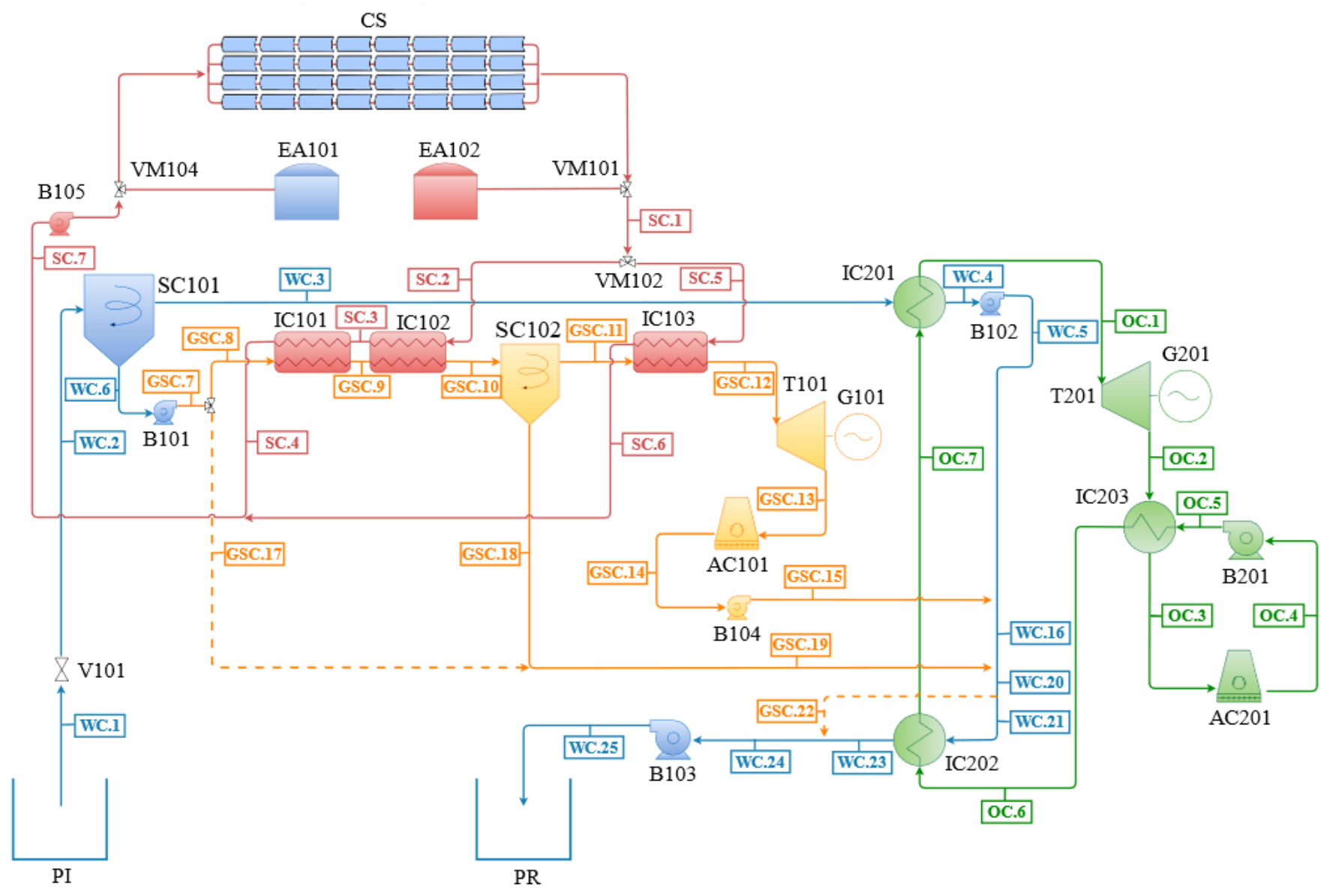

Figure 5. Hybrid Solar-Geothermal power plant integration diagram (CH01).

The proposed scheme was evaluated under two nominal thermal capacities, 30 and $40 \mathrm{MW}$. In addition to that, the nominal cold and hot temperatures of the HTF were ranged from 200 to $240{ }^{\circ} \mathrm{C}$, and from 370 to $390^{\circ} \mathrm{C}$, respectively, in 15 different configurations of solar field and TES size (see Table A3). In particular, the configuration $\mathrm{CH} 01$ with a thermal 
capacity of $40 \mathrm{MW}$ considers that the GSC.17 stream is null for maintaining the energy and mass balances.

\subsubsection{Hybrid Scheme $\mathrm{CHO}$}

Associated with the increase of the thermal power available, the steam generation in (IC102) will also increase. Thereby, the condensed steam from (AC101) impacts on the mixture quality in (WC.5). Additionally, the lower brine production in (GSC.18), at higher temperatures, is useless to increase the temperature at (GSC.16), affecting the operation of (IC202). The silica precipitation risk is higher in the reinjection process. For that reason, a new configuration is proposed for solar fields larger than $50 \mathrm{MW}$ of thermal capacity, as shown in Figure 6. In this scheme, an additional heat exchanger (IC104) is introduced to the configuration (CH02), which allows increasing the temperature at the preheater inlet (IC202). Thus, this stream is kept near to the reference temperature.

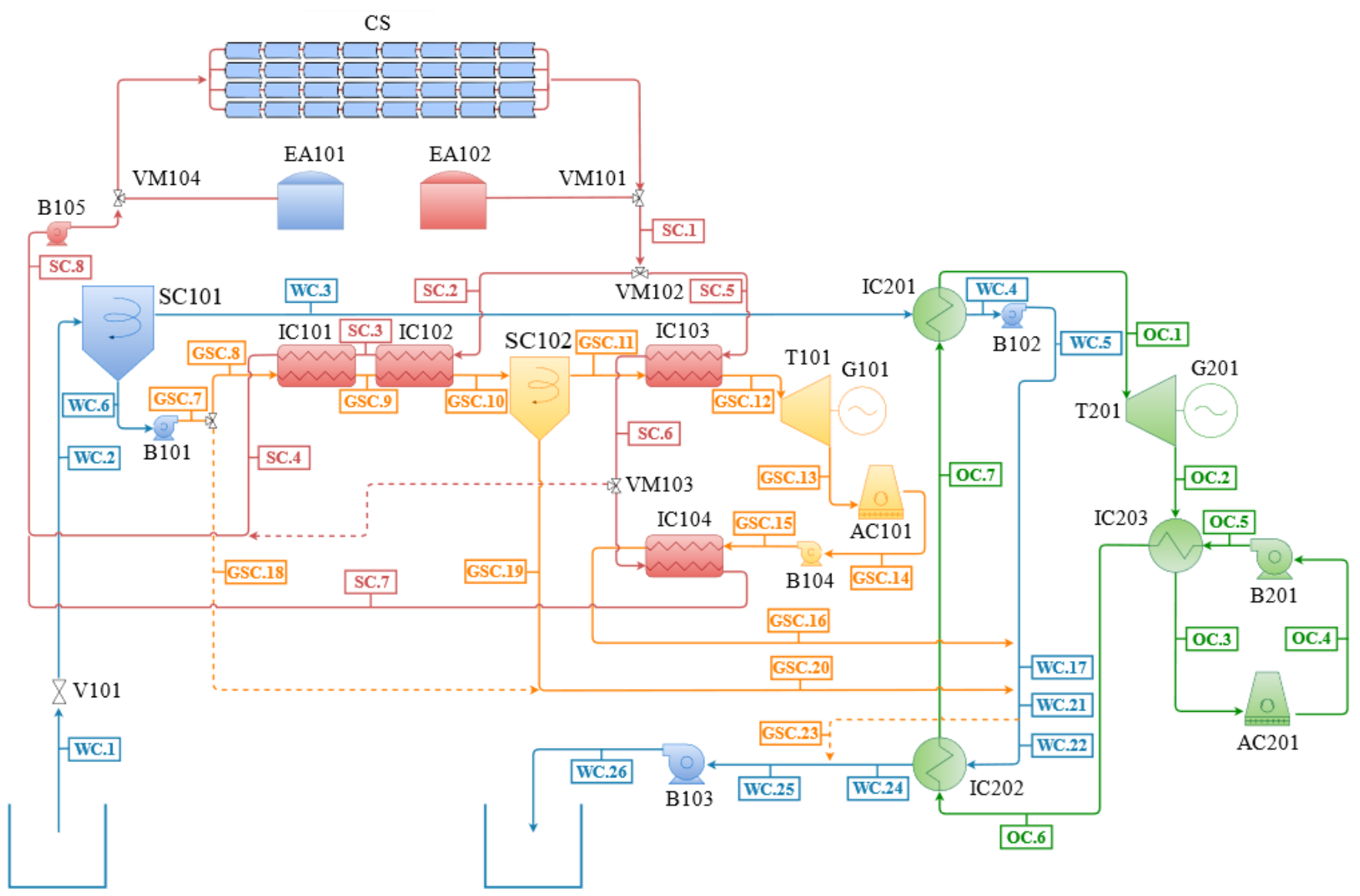

Figure 6. Hybrid Solar-Geothermal power plant integration diagram (CH02).

\section{Thermodynamic Analysis}

A computational model was developed for analyzing the yield of Cerro Pabellón geothermal plant, considering the actual layout of the plant( courtesy of ENEL S.A.). In addition, two hybrid integration schemes coupling a PTC solar field and the geothermal system were considered. The modelling of the three configurations, the base case, and the two proposed hybrid schemes, was developed using the Engineering Equation Solver software (EES) [32]. Likewise, the yield of the solar thermal system was modeled using the dedicated module in the System Advisor Model (SAM) [33], which is coupled to the main computational model in EES.

Three different configurations were analyzed: (1) the base case corresponding to the actual configuration of Cerro Pabellón geothermal power plant; (2) CH01 for a solar field of 30 and $40 \mathrm{MW}$ thermal capacity; and (3) CH02 for a solar thermal capacity of 50 and $60 \mathrm{MW}$. 
The following assumptions were enforced, associated to the current operation parameters of Cerro Pabellón power plant:

- $\quad$ The HTF in the ORC is isopentane;

- Condensation system: ACC (Air cooled condenser);

- Geothermal fluid reinjection: $100 \%$;

- Geothermal fluid from the wells: two-phase mixture;

- The average ambient temperature is $3.88^{\circ} \mathrm{C}$ and the atmospheric pressure is $59.1 \mathrm{kPa}$ (from the TMY database).

In addition to that, to carry out the thermodynamic model, the following assumptions were also established:

- The three cycles studied were simulated under quasi-steady state conditions;

- Equipment and pipelines are considered adiabatic and the pressure drop is neglected, except in case (3);

- Geothermal brine thermodynamic properties are represented by the demineralized water properties;

- The simulation does not consider non-condensable gases;

- Kinetic and potential energy were neglected in the energy conservation equations;

- Turbine isentropic efficiency is $85 \%$;

- Pump isentropic efficiencies is $80 \%$;

- Turbines and pumps are adiabatic;

- Generator efficiency is $98 \%$.

The 1st law of thermodynamics is applied in each component of the cycle, as follows,

$$
\dot{Q}+\dot{W}=\Sigma \dot{m}_{\text {in }} h_{\text {in }}-\Sigma \dot{m}_{\text {out }} h_{\text {out }},
$$

where $\dot{Q}$ is the heat transfer rate from or to the system, $\dot{W}$ is the work delivered by or to the system, $m$ is the mass flow rate, $h$ is the specific enthalpy, and the subscripts in and out refer to inlet and outlet, respectively.

To determine the exergy rates in each component of the hybrid system, the exergy balance was applied as suggested in [34]. The general equation holds as follows:

$$
\dot{X}_{\text {heat }}-\dot{W}+\Sigma \dot{X}_{\text {in }}-\Sigma \dot{X}_{\text {out }}-\left(\dot{X}_{\text {dest }}+\dot{X}_{\text {loss }}\right)=0,
$$

where $\dot{X}_{\text {heat }}$ is the exergy transfer rate by heat, $\dot{X}_{\text {in }}$ and $\dot{X}_{\text {out }}$ are the inlet and outlet exergy rates, respectively. The subscripts dest and loss represent the destroyed and lost exergy rate, respectively. The term $\left(\dot{X}_{\text {loss }}\right)$ is only evaluated considering the operation of an air-cooled condenser. The exergy rate due to heat transfer rate is obtained using the following equation:

$$
\dot{X}_{\text {heat }}=\Sigma\left(1-\frac{T_{0}}{T_{k}}\right) \dot{Q}_{k},
$$

where $T_{0}$ is the ambient temperature (dead state) and $T_{k}$ corresponds to the heat source temperature.

The exergy rate for a state $i$ is expressed as:

$$
\dot{X}_{i}=\dot{m}_{i} \psi_{i}
$$

where $\psi_{i}$ is

$$
\psi_{i}=\left(h_{i}-h_{0}\right)-T_{0}\left(s_{i}-s_{0}\right),
$$

where $h_{i}$ and $s_{i}$ are the enthalpy and entropy for state $i$, and $h_{0}$ and $s_{0}$ are the enthalpy and entropy at dead state (average ambient temperature and atmospheric pressure).

To evaluate the overall thermal performance of the geothermal and solar thermal systems, the thermal efficiency is defined as follows: 


$$
\eta_{t h}=\frac{\dot{W}_{O R C}+\dot{W}_{G S C}}{\dot{Q}_{g e o}+\dot{Q}_{\text {solar }}},
$$

where the subscript GSC is associated with the geothermal solar cycle, and $\dot{Q}_{s f}$ is the heat delivered by the solar field.

To evaluate the benefits of integrating solar and geothermal resources, the exergy efficiency is applied as an additional metric. Through this assessment, it is possible to determine, using a rational approach, the best approach to manage the energy resources to exploit its energetic potential. The exergy efficiency is defined as follows:

$$
\eta_{e x}=\frac{\dot{W}_{O R C}+\dot{W}_{G S C}}{\dot{X}_{g e o}+\dot{X}_{s f}},
$$

where $\dot{X}_{g e o}$ and $\dot{X}_{s f}$ is expressed as:

$$
\dot{X}_{\text {source }}=\dot{m}_{\text {source }}\left[\left(h_{\text {source, in }}-h_{\text {source, out }}\right)-T_{0}\left(s_{\text {source, in }}-s_{\text {source,out }}\right)\right] \text {, }
$$

where the subscript source corresponds to geo or $s f$, as corresponds.

\subsection{Heat Exchangers}

Because of the hybridization, additional heat exchangers were integrated to the system, as depicted in the diagrams of Figures 5 and 6. IC101 and IC102 allow preheating and partially evaporating the geothermal brine, IC103 is used as a steam superheater before the turbine, and IC104 allows increasing the temperature of the geothermal fluid previous to the condensation system. IC101 and IC102 work in series, as well as the heat exchangers IC103 and IC104.

To determine the mass flow rate in the heat exchangers IC101 and IC102, it is defined a by-pass factor $(f)$, which is established to keep an equivalent temperature in the superheated steam before entering the turbine. Thus, the mass flow rate in IC101-102 is defined by:

$$
\dot{m}_{s f, f 1}=f \dot{m}_{s f},
$$

while the mass flow rate in the heat exchangers IC103 and IC104 is:

$$
\dot{m}_{h t f, f 2}=(1-f) \dot{m}_{h t f} .
$$

In nominal conditions, a constant of proportionality $k$ is established between the synthetic oil (Therminol VP-1) mass flow rate $\left(\dot{m}_{s f, f 1}\right)$, and geothermal brine $\left(\dot{m}_{g b, i n}\right)$, as is established according to the following equation:

$$
k=\frac{\dot{m}_{g b, i n}}{\dot{m}_{h t f, f 1}}
$$

where the constant $k$ is used to keep the controlled geothermal brine through the heat exchangers IC101 and IC102, when there are changes in thermal oil mass flow rate.

The sizing and rating of the additional heat exchangers considered for the hybrid schemes are determined through the following equation:

$$
\dot{Q}=U A \Delta T_{L M T D},
$$

where $\dot{Q}$ is the thermal power transferred, $U$ is the global heat transfer coefficient, $A$ is the heat transfer area, and $\Delta T_{L M T D}$ is the logarithmic mean temperature difference, which for a counter flow heat exchanger is expressed as: 


$$
\Delta T_{L M T D}=\frac{\Delta T_{1}-\Delta T_{2}}{\ln \left(\frac{\Delta T_{1}}{\Delta T_{2}}\right)},
$$

where the temperature differences are defined as:

$$
\begin{gathered}
\Delta T_{1}=T_{\text {hot,in }}-T_{\text {cold,in }} \\
\Delta T_{2}=T_{\text {hot,out }}-T_{\text {cold,in }} .
\end{gathered}
$$

The heat transfer coefficient $U$ is established in the range between 100 to $450 \mathrm{~W} /\left(\mathrm{m}^{2} \mathrm{~K}\right)$ for the oil/water heat exchangers, according to Nellis2009 [35]. On the other hand, for the condensation system the $U$ value is within the range of 300 to $450 \mathrm{~W} /\left(\mathrm{m}^{2} \mathrm{~K}\right)$.

The heat exchanger effectiveness is defined as follows:

$$
\epsilon=\frac{\dot{Q}}{\dot{Q}_{\max }}=\frac{\text { Real heat transfer rate }}{\text { Maximum heat transferable rate }},
$$

where $\dot{Q}_{\max }$ is the maximum heat transfer rate, expressed as:

$$
\dot{Q}_{\text {max }}=\dot{C}_{\min } \Delta T_{\max }=\dot{C}_{\min }\left(T_{\text {hot, in }}-T_{\text {cold, }, \text { in }}\right)
$$

and $\dot{C}_{\min }$, is the minimum heat capacitance of the streams in the heat exchanger, which determined using the following expression:

$$
\dot{C}_{\text {min }}=\min \left(\dot{C}_{\text {hot }}, \dot{C}_{\text {cold }}\right)=\min \left(C_{p, h o t} \dot{m}_{\text {hot }}, C_{p, \text { cold }} \dot{m}_{\text {cold }}\right) \text {. }
$$

Likewise, the effectiveness of a counter flow heat exchanger is defined according to Nellis2009 [35], as follows:

$$
\epsilon=\frac{1-e^{-N T U\left(1-C_{r}\right)}}{1-C_{r} e^{-N T U\left(1-C_{r}\right)}},
$$

where NTU is the number of transfer unit defined as the ratio between $U A$ and $\dot{C}_{\text {min }}$, and $C_{r}$ is the ratio of $\dot{C}_{\min }$ and $\dot{C}_{\max }$.

$$
\begin{gathered}
N T U=\frac{U A}{\dot{C}_{\text {min }}} \\
C_{r}=\frac{\dot{C}_{\min }}{\dot{C}_{\max }}=\frac{\min \left(C_{p, h o t} \dot{m}_{\text {hot }}, C_{p, \text { cold }} \dot{m}_{\text {cold }}\right)}{\max \left(C_{p, h o t} \dot{m}_{\text {hot }}, C_{p, \text { cold }} \dot{m}_{\text {cold }}\right)} .
\end{gathered}
$$

\subsection{Air-Cooled Condenser}

The power consumption associated with the operation of the fan in air-cooled condensers is set at $0.13 \mathrm{~kW} / \dot{m}_{\text {air }}$, according to Ciani_Bassetti2018-ni [26]. Thus, the energy balance in the condensation process is described as:

$$
\dot{Q}_{A C}=\dot{m}_{o}\left(h_{o, \text { in }}-h_{o, \text { out }}\right)=\dot{m}_{o}\left(h_{\text {air, hot }}-h_{\text {air }, \text { cold }}\right),
$$

where $\dot{Q}_{A C}$ is the thermal power output due to the condensation of isopentane. According to the exergy balance, the exergy flow transferred to the air is considered as exergy loss and is defined as:

$$
\dot{X}_{\text {loss }}=\dot{m}_{o}\left(\psi_{0, \text { in }}-\psi_{0, o u t}\right) \text {. }
$$

\subsection{Turbine}

The power produced by the turbines was estimated by assuming adiabatic operation and disregarding the friction losses. Thus, the mechanical power generated in the turbine is expressed as: 


$$
\dot{W}_{\text {mec }}=\dot{m}_{T}\left(h_{T, \text { in }}-h_{T, \text { out }}\right)=\dot{m}_{T} \eta_{T, s}\left(h_{T, \text { in }}-h_{T, \text { out }, s}\right),
$$

where $\dot{W}_{m e c}$ is mechanically power generated in turbine, $\eta_{T, s}$ is the isentropic efficiency. For determining the value of $\eta_{T, S}$ it is employed the Baumann's rule [36], which describes the loss in efficiency that represents the wet expansion in terms of the engine performance. Thus, the isentropic efficiency is determined using the following equation:

$$
\eta_{T, \mathrm{~s}}=\eta_{T, d}\left(\frac{x_{\text {in }}-x_{\text {out }}}{2}\right)
$$

where $\eta_{T, d}$ is the efficiency in dry expansion process, which is considered 0.85 for the present study, $x_{\text {in }}$ and $x_{\text {out }}$ correspond to the steam quality at the inlet and outlet conditions, respectively. Finally, the turbine drives a generator with an efficiency $\eta_{g}$, so the electricity generated is expressed as:

$$
\dot{W}_{e l}=\eta_{g} \dot{W}_{m e c}
$$

\subsection{Solar Collector Field and Thermal Energy Storage}

PTC were chosen to be considered in the hybrid solar geothermal schemes, considering its availability in the market and that PTC are considered a mature technology. The yield of the solar field was simulated in SAM, which simulation considers the local meteorological conditions, the efficiency parameters of the collectors, the solar field layout, partial load performance profile, and the thermophysical properties of the HTF used in simulations. The reference irradiance was considered as $1100 \mathrm{~W} / \mathrm{m}^{2}$ which represents the $85 \%$ percentile of the TMY database. The aforementioned parameters are summarized in Table 1.

Table 1. SAM input parameters.

\begin{tabular}{cc}
\hline Parameter & \\
\hline PTC type & EuroTrough ET150 \\
Solar field HTF & Therminol VP-1 \\
PTC receiver type & Schott PRT-70 \\
Tracking & North-South \\
Reference Irradiance & $1100 \mathrm{~W} / \mathrm{m}^{2}$ \\
\hline
\end{tabular}

A parametric evaluation was carried out to analyze the integration of the solar and geothermal systems, where the solar field nominal conditions were varied. The parameters considered in this parametric assessment are the nominal thermal power delivered from the solar field to the system, the solar multiple, the size of the storage system, and the outlet and inlet temperatures of the solar collectors. Thus, it aroused in 4620 integration strategies that were are analyzed in the parametric evaluation, which are summarized in Table 2.

Table 2. Nominal condition for solar thermal plant.

\begin{tabular}{lcc}
\hline Parameter & Range & Step \\
\hline Thermal power (MWth) & $30-60$ & 10 \\
Solar multiple $(-)$ & $1.0-3.0$ & 0.2 \\
Storage hours $(\mathrm{h})$ & $0-12$ & 2 \\
Output temperature $\left({ }^{\circ} \mathrm{C}\right)$ & $370-390$ & 10 \\
Inlet temperature $\left({ }^{\circ} \mathrm{C}\right)$ & $200-240$ & 10 \\
\hline
\end{tabular}

\subsection{Silica Precipitation}

Geothermal conversion systems are susceptible to mineral precipitation, which may affect the power cycle operation or even change the permeability conditions in the reinjection well. Because of that, considering that the hybrid schemes proposed herein would 
change the operation point of the geothermal system, the present study considers a verification of the silica precipitation risk. Such procedure allows determining the exposure to precipitation in each stream of the geothermal system.

Silica precipitation could occur in different structural shapes, from amorphous silica to crystalline (such as quartz). These have different solubility curves, and the temperature could affect silica precipitation. Due to the different solubility curves, each stream in the geothermal cycle has a different precipitation risk. For instance, the geothermal well may control quartz formation, while amorphous silica formation may be controlled when the geothermal fluid transfers heat to the power cycle.

Silica solubility is temperature, $\mathrm{pH}$, and salinity dependent; however, for the present analysis salinity and $\mathrm{pH}$ are assumed as constants. Hence, the silica concentration is evaluated in temperature terms. According to DiPippo2012 [36] the concentration at the initial state is expressed as:

$$
Q\left(T_{r}\right)=41.598+0.23932 T_{r}+0.011172 T_{r}^{2}+1.1713 \cdot 10^{-4} T_{r}^{3}-1.9708 \cdot 10^{-7} T_{r}^{4},
$$

where $T_{r}$ is geothermal fluid temperature (expressed in Celsius) at extraction from the well and $Q\left(T_{r}\right)$ corresponds to the concentration in $\mathrm{mg} / \mathrm{kg}$. Regarding the silica solubility in pure water, it is temperature dependant as described by the following equation proposed by [37]:

$$
\log _{10}\left(S_{\text {sat }}\right)=4.52-\frac{731}{T+237.15}
$$

where $S_{\text {sat }}$ is in $\mathrm{mg} / \mathrm{kg}$ or $\mathrm{ml} / \mathrm{kg}$, and the temperature ranges between 0 to $250^{\circ} \mathrm{C}$.

Due to the steam generation and separation process, the silica concentration increases, as stated by the following expression [36]:

$$
S=\frac{Q}{1-x}
$$

where $x$ is the quality of the geothermal two-phase mixture and $S$ is the amorphous silica concentration.

To integrate silica precipitation risk in the simulations, it is assumed that mineral oversaturation occurs when the brine reaches temperatures lower or equal to $85^{\circ} \mathrm{C}$. Therewith, the value of $Q_{r}$ is $300.6 \mathrm{mg} / \mathrm{kg}$. This value is used as a threshold to analyze the stream where precipitation could occur. Therefore, to evaluate the precipitation risk in Cerro Pabellón is defined $R_{c r i t, i}$ as critic ratio, expressed as:

$$
R_{c r i t, i}=\frac{S_{i}}{S_{s a t}}
$$

where $S_{i}$ is the silica concentration in $\mathrm{i}$, and $S_{\text {sat }}$ is the value where mineral precipitation begins, considering the temperature in this state.

In the base case configuration (see Figure 4), states (WC.6) and (WC.9) present higher precipitation risk, 0.53 and 0.93 , respectively. Due to these results, it is pointed out that higher risks are observed at the reinjection stage. In the analyses of the integration strategies, the operation of the ORC is not affected, since the state with higher precipitation risk is in (WC.10), after partial evaporation of brine, where the silica concentration increases due to the evaporation. However, the critic ratio in this stream must not exceed 0.6 , reaching 0.524 in $\mathrm{CH} 01-30,0.526$ for $\mathrm{CH} 01-40,0.539$ in $\mathrm{CH} 02-50$ and 0.553 in $\mathrm{CH} 02-60$ integration strategy, bringing a low risk of silica precipitation in all cases analyzed.

\subsection{Economic Evaluation}

The comparison of the integration strategies is carried out in terms of the Levelized Cost of Energy (LCOE). This economic parameter allows assessment of the investment and operational costs associated with electricity production in the project lifetime. The LCOE definition is expressed as follows: 


$$
L C O E=\frac{I_{0}+\sum_{t=1}^{n}\left(\frac{A_{t}}{(1+j)^{t}}\right)}{\sum_{t=1}^{n}\left(\frac{M_{t, e l}}{(1+j)^{t}}\right)},
$$

where $I_{0}$ is the initial investment, $A_{t}$ and $M_{t, e l}$ are operation and maintenance costs $(\mathrm{O} \& \mathrm{M})$, and electric production in year $t$, respectively. $j$ corresponds to the discount rate and $n$ is the project lifetime assumed in $7 \%$ and 30 years, respectively. The numerical values of the economic parameters considered for the evaluation are summarized in Table 3, which follows the recommendations in [38].

Table 3. Power block and solar field costs.

\begin{tabular}{|c|c|c|c|}
\hline System & Sub-System & Value & Unit \\
\hline \multicolumn{4}{|l|}{ Direct costs } \\
\hline Site improvements & - & 15 & $\mathrm{US} \$ / \mathrm{m}^{2}$ \\
\hline Solar field & - & 100 & $\mathrm{US} \$ / \mathrm{m}^{2}$ \\
\hline \multirow[t]{3}{*}{ Heat transfer fluid } & Piping & 27.7715 & $\mathrm{US} \$ / \mathrm{m}^{2}$ \\
\hline & Other & 10.2285 & $\mathrm{US} \$ / \mathrm{m}^{2}$ \\
\hline & Fluid & 21 & $\mathrm{US} \$ / \mathrm{kW}$ \\
\hline \multirow{7}{*}{ Thermal energy storage } & Heat exchangers & 3.225 & US\$/kWh \\
\hline & Cold tank & 1.326 & US\$/kWh \\
\hline & Hot tank & 3.05 & US $\$ / \mathrm{kWh}$ \\
\hline & HTF & 8.869 & US\$/kWh \\
\hline & Grounds & 1.365 & US $\$ / \mathrm{kWh}$ \\
\hline & Insulation & 1.014 & $\mathrm{US} \$ / \mathrm{kWh}$ \\
\hline & Instruments & 0.2106 & US\$/kWh \\
\hline \multirow{3}{*}{ Power block } & Turbine & 308.11 & $\mathrm{US} \$ / \mathrm{kW}$ \\
\hline & Others & 416.48 & $\mathrm{US} \$ / \mathrm{kW}$ \\
\hline & Cooling & 178.08 & US\$/kW \\
\hline BOP & Balance of plant & 97.34 & $\mathrm{US} \$ / \mathrm{kW}$ \\
\hline Indirect costs & - & $11 \%$ & $\%$ \\
\hline Site cost & - & 0 & US\$/acre \\
\hline EPC and Owner Costs & - & 0 & $\%$ of direct costs \\
\hline Contingencies & - & $7 \%$ & $\%$ \\
\hline \multicolumn{4}{|l|}{ O\&M costs } \\
\hline Fixed costs & - & 66 & US\$/kW-yr \\
\hline Variable costs & - & 3 & US\$/MWh \\
\hline
\end{tabular}

\section{Results and Discussion}

Steady-state and transient simulations were made to evaluate the integration strategies. First, steady-state simulations were conducted for dimensioning the solar field, the TES system, and power block heat exchangers. The simulations considered a thermodynamic and exergy analysis in nominal conditions, and a cost analysis accounting the hybridization of solar and geothermal plants. Afterwards, transient simulations were performed allowing an accurate assessment of the electricity generation and the LCOE estimation. The results of the sizing procedure for the aforementioned integration schemes are summarized in Appendix A.

\subsection{Thermodynamic Analysis}

To evaluate the integration strategies, the superheating temperatures of the geothermal steam and the brine at the reinjection point were defined as equivalent for all alternatives analyzed. Hence, these two temperature values are independent of the solar field and thermal oil temperatures. Thereby, similar thermodynamic behaviors between the scenarios 
are observed, to show graphically this behavior a temperature-entropy (T-s) diagram is shown in Figure 7, specifically for the $\mathrm{CH} 2$ scheme, considering a 60 MWof thermal capacity at the solar field. Figure 7 depicts the thermodynamic states of the solar geothermal cycle, where the numbers correspond to those states depicted in Figure 6.

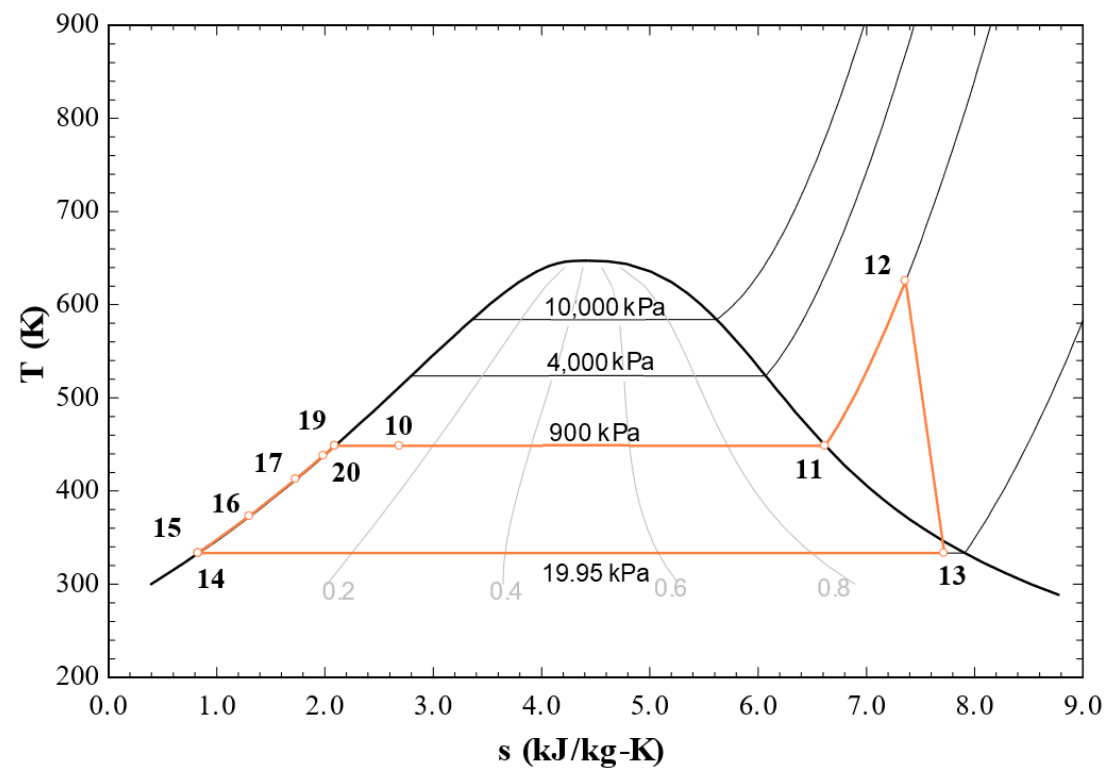

Figure 7. T-s diagram for $\mathrm{CH} 2-60$ integration alternative.

Table 4 shows the additional steam production, as well as the additional power capacity due to the solar geothermal cycle, in function of the nominal thermal capacity of the solar field. It is observed that the steam production from geothermal brine and electricity production increases gradually due to the rise of the thermal supply. In average, the steam generated increases in $3.44 \mathrm{~kg} / \mathrm{s}$ when $10 \mathrm{MW}$ of solar thermal capacity are coupled to the geothermal system. Regarding to the electricity generation, an additional $1984 \mathrm{~kW}$ are delivered with the addition of $10 \mathrm{MW}$ of solar thermal capacity. Therewith, a specific metric to measure the electricity generation is defined for the hybrid schemes: an additional $198 \mathrm{~kW}$ are delivered per MW of solar thermal capacity introduced to the system.

Table 4. Main performance indicators in function of thermal power delivered by the solar field.

\begin{tabular}{lcccc}
\hline \multicolumn{1}{c}{ Production $\left(\mathbf{M W}_{\text {th }}\right.$ ) } & $\mathbf{3 0}$ & $\mathbf{4 0}$ & $\mathbf{5 0}$ & $\mathbf{6 0}$ \\
\hline Steam production $(\mathrm{kg} / \mathrm{s})$ & 10.01 & 13.46 & 16.89 & 20.32 \\
Solar cycle-Total extra capacity $\left(\mathrm{kW}_{\mathrm{el}}\right)$ & 5789 & 7784 & 9765 & 11,750 \\
Solar cycle-Thermal efficiency $(\%)$ & 19.30 & 19.46 & 19.53 & 19.58 \\
Hybrid cycle-Total extra capacity $\left(\mathrm{kW}_{\mathrm{el}}\right)$ & 29,567 & 31,562 & 33,543 & 35,528 \\
Hybrid cycle-Thermal efficiency $(\%)$ & 17.73 & 17.86 & 17.97 & 18.06 \\
\hline
\end{tabular}

Regarding the thermal efficiency of the hybrid scheme, it is observed a slight increase as the thermal power of the solar field rises, where $19.58 \%$ is the maximum value achieved when the power cycle is coupled to a $60 \mathrm{MW}$ solar field. These efficiencies are lower than observed in the literature [39], which are commonly close to $35 \%$. The reduction is explained by the restriction established to the hybrid system, particularly by the silica precipitation constraint that prevents operating the condensing stages at lower temperatures. Regarding the efficiency of the hybrid system, the higher value is reached when the solar field presents a thermal capacity of $60 \mathrm{MW}$, with an efficiency of $18.06 \%$. This value is $0.67 \%$ higher than the geothermal standalone plant, which corresponds to $17.39 \%$. 


\subsection{Exergy Analysis}

The analysis of the exergy efficiency allows assessing the quality of processes that occur in the hybrid scheme. To illustrate the exergy performance of the solar system when coupled in the hybrid scheme, it was considered four integration scenarios (30, 40, 50 and $60 \mathrm{MW}$ ), where the solar field operating at different inlet and outlet temperatures. The results of the scenarios analyzed are summarized in Figure 8, where the maximum exergy efficiency within the solar field capacities analyzed was reached when the nominal temperatures were $T_{c}=200^{\circ} \mathrm{C}$ and $T_{h}=370{ }^{\circ} \mathrm{C}$.

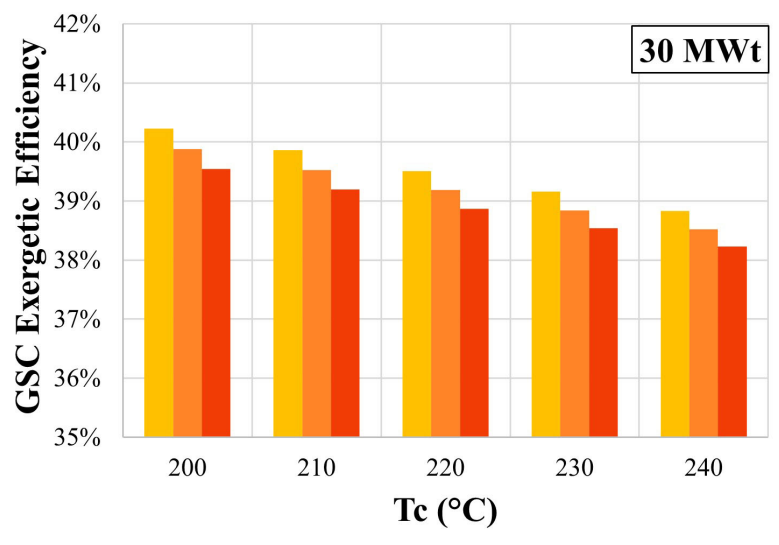

(a)

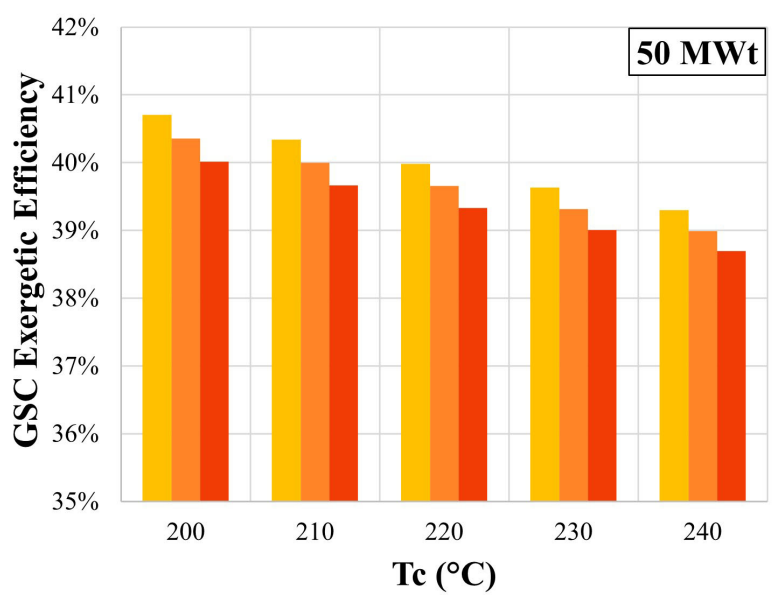

(c)

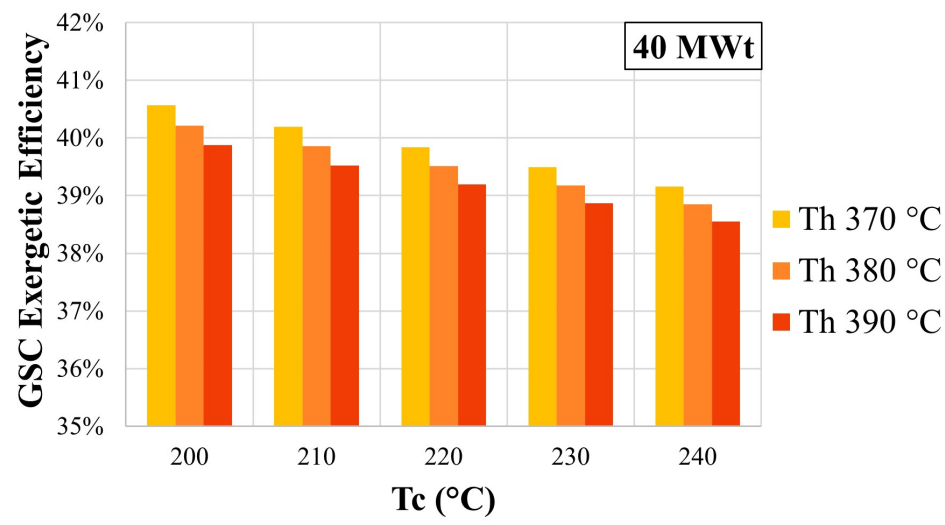

(b)

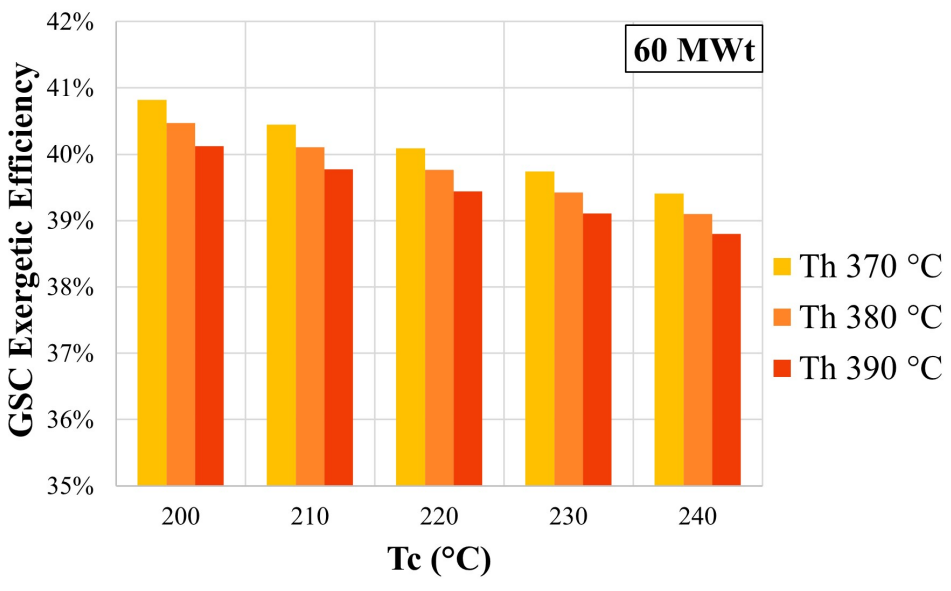

(d)

Figure 8. Solar cycle exergy efficiency, function of thermal energy delivered by solar thermal field. (a) Case: Solar Thermal Input of $30 \mathrm{MW}_{\text {th }}$; (b) Case: Solar Thermal Input of $40 \mathrm{MW}_{\text {th }}$; (c) Case: Solar Thermal Input of $50 \mathrm{MW}_{\mathrm{th}}$; (d) Case: Solar Thermal Input of $60 \mathrm{MW}_{\mathrm{th}}$.

The exergy flow provided by the solar field is distributed in three terms $\dot{X}_{\text {out }}, \dot{X}_{\text {dest }}$ and $\dot{X}_{\text {loss }}$, where the first represents the useful work (which reaches the same value than considered for the exergy efficiency), the second is the exergy destroyed in the processes, and the latter is the exergy released to the environment at the air-cooled condenser. Table 5 presents the results obtained for the solar field of $60 \mathrm{MW}$ thermal capacity. High levels of exergy destruction are observed for these configurations, where on average $33.5 \%$ of exergy flows were destroyed. The main source of exergy destruction is associated with the operation of the heat exchangers IC101 and IC102. However, similar behaviors in exergy destruction are observed for all scenarios analyzed in the present work. 
Table 5. Distribution of the exergy rate in the solar thermal system, considering $T_{h}=370{ }^{\circ} \mathrm{C}$ and $T_{\mathcal{C}}=200^{\circ} \mathrm{C}$.

\begin{tabular}{ccccccccccc}
\hline $\begin{array}{c}\text { Thermal } \\
\text { Capacity (MW }\end{array}$ th & $\dot{X}_{\text {out }}$ & $\dot{X}_{\text {dest }}$ & $\dot{X}_{\text {loss }}$ & \multicolumn{7}{c}{$\dot{X}_{\text {loss }}$ by Component } \\
\hline & & & & IC101-IC102 & IC103 & IC104 & T101 & B104 & CMs & G101 \\
\hline 30 & $40.22 \%$ & $34.1 \%$ & $25.67 \%$ & $64.7 \%$ & $2.1 \%$ & - & $20.2 \%$ & - & $10.5 \%$ & $2.5 \%$ \\
40 & $40.56 \%$ & $33.55 \%$ & $25.89 \%$ & $64.8 \%$ & $2.1 \%$ & - & $20.4 \%$ & - & $10.1 \%$ & $2.6 \%$ \\
50 & $40.71 \%$ & $33.31 \%$ & $25.98 \%$ & $62.2 \%$ & $3.5 \%$ & $5 \%$ & $20.5 \%$ & $0 \%$ & $6.2 \%$ & $2.6 \%$ \\
60 & $40.82 \%$ & $33.13 \%$ & $26.05 \%$ & $62.46 \%$ & $4.07 \%$ & $8.01 \%$ & 20.6 & $0.04 \%$ & $4.25 \%$ & $2.58 \%$ \\
\hline
\end{tabular}

\subsection{Cost Estimation of the Integration Strategies}

The estimation of the component costs for the solar geothermal hybrid scheme was carried out considering the installation costs for the different configurations. That considers the variations associated with the different solar thermal capacities and nominal operation temperatures of the thermal oil, resulting in 60 scenarios. Table 6 summarizes the cost of the steam power block for every configuration, considering the assumptions described in Table 3. It is observed that for the same thermal capacity and, therefore, the same aperture area of the solar field, different costs are estimated. That result is explained by the difference in the nominal operating temperatures of the thermal oil, which causes different heat exchanger sizes and amount of thermal oil in the system.

Table 6. Power block cost estimation (MUS\$).

\begin{tabular}{cccccl}
\hline $\begin{array}{c}\text { Thermal Capacity }\left(\mathbf{M W}_{\mathbf{t h}}\right) \\
\text { Aperture Area }\left(\mathbf{m}^{2}\right)\end{array}$ & $\mathbf{3 0}$ & $\mathbf{4 0}$ & $\mathbf{5 0}$ & $\mathbf{6 0}$ & $\begin{array}{c}\text { Nominal Operating } \\
\text { Temperatures }\left({ }^{\circ} \mathbf{C}\right)\end{array}$ \\
\hline & $\mathbf{3 9 , 2 4 0}$ & $\mathbf{5 2 , 3 2 0}$ & $\mathbf{6 3 , 1 3 0}$ & $\mathbf{7 5 , 2 1 0}$ & $\begin{array}{c}\text { Temp } \\
\end{array}$ \\
\hline .28 & 10.73 & 12.88 & 15.2 & $T h=390, T c=200$ \\
& 8.2 & 10.62 & 12.78 & 15.09 & $T h=390, T c=210$ \\
& 8.14 & 10.54 & 12.71 & 15.01 & $T h=390, T c=220$ \\
& 8.09 & 10.48 & 12.66 & 14.94 & $T h=390, T c=230$ \\
Costs (MMUS\$) & 8.34 & 10.43 & 12.61 & 14.89 & $T h=390, T c=240$ \\
& 8.25 & 10.69 & 12.94 & 15.27 & $T h=380, T c=200$ \\
& 8.18 & 10.6 & 12.77 & 15.16 & $T h=380, T c=210$ \\
& 8.13 & 10.53 & 12.71 & 15.00 & $T h=380, T c=220$ \\
& 8.09 & 10.48 & 12.66 & 14.94 & $T h=380, T c=230$ \\
& 8.43 & 10.93 & 13.04 & 15.37 & $T h=370, T c=200$ \\
& 8.32 & 10.79 & 12.94 & 15.25 & $T h=370, T c=210$ \\
& 8.24 & 10.68 & 12.85 & 15.16 & $T h=370, T c=220$ \\
& 8.18 & 10.6 & 12.78 & 15.08 & $T h=370, T c=230$ \\
& 8.14 & 10.54 & 12.73 & 15.02 & $T h=370, T c=240$ \\
\hline
\end{tabular}

\subsection{Annual Production}

Hereafter, it is presented the yield of the hybrid solar geothermal scheme on an annual basis, considering the different configurations established in the previous sections. To describe the daily behavior, Figure 9 shows the electricity production of the hybrid power plant for the $\mathrm{CH} 02-60 \mathrm{MW}$ configuration, considering a solar multiple of 1 and no TES. The electricity production associated with the solar and geothermal subcycles are shown separated, since the operation condition of the ORC has not changed. Due to the hybridization it is possible to increase the electrical production in $12 \mathrm{MW}$, reaching $36 \mathrm{MW}$ during the daylight hours. Meanwhile, the electricity generation by the ORC is constant: $24 \mathrm{MW}$, not being affected by hybridization. 


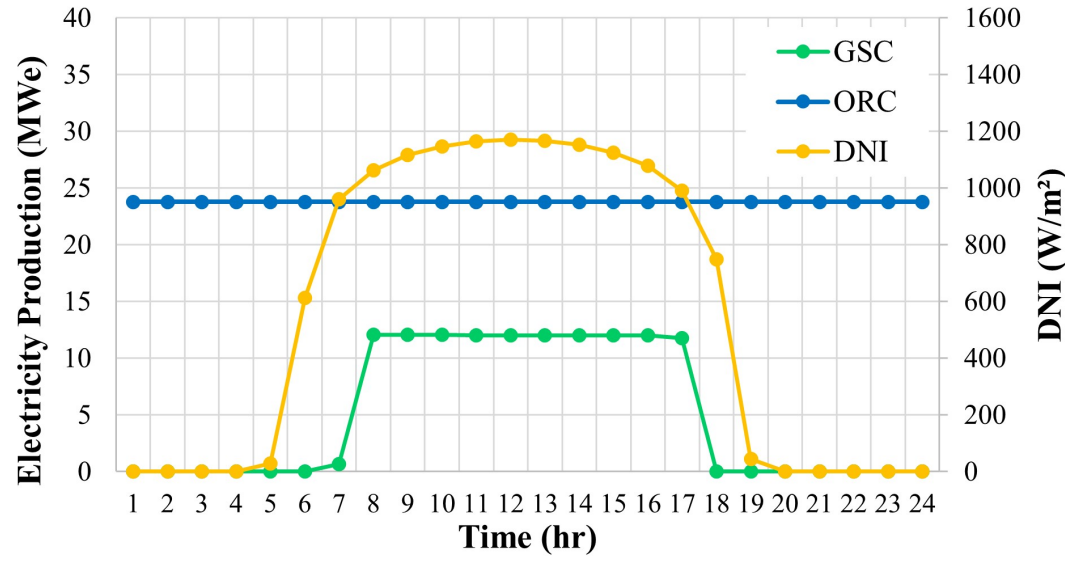

Figure 9. Electric production profile for hybrid solar-geothermal plant on January 3rd from the TMY file for the $\mathrm{CH} 02-60$ integration scenario.

Continuing with the $\mathrm{CH} 02-60$ scenario, Figure 10 shows the annual production in hourly basis, which corresponds to the hybrid solar geothermal scheme with a solar multiple of 1 and no TES. As observed, the electricity generation is consistent with the DNI availability (see Figure 2), showing an annual generation of $23.1 \mathrm{GWh}$, while the capacity factor of the solar thermal plant was $21.9 \%$.

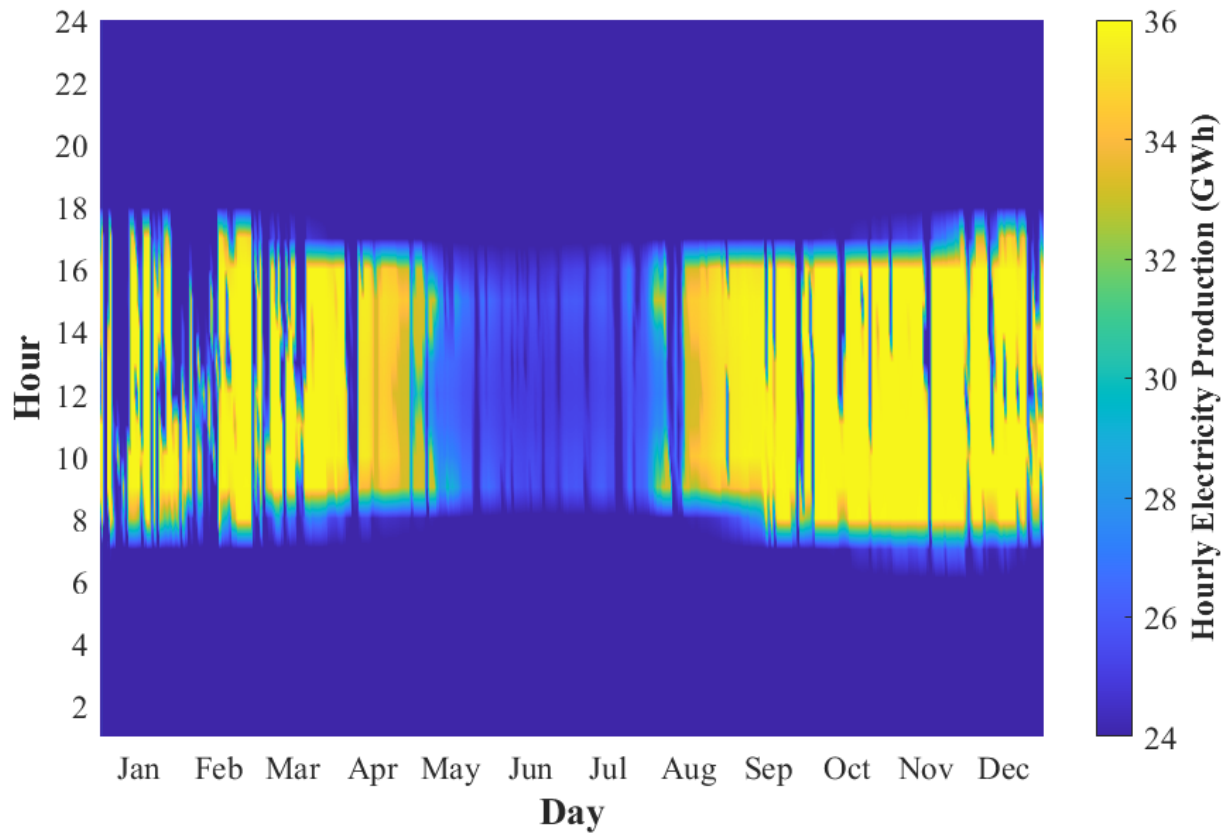

Figure 10. Electricity production profile for configuration scenario $\mathrm{CH} 02-60$, considering $\mathrm{SM}=1$ and TES $=0 \mathrm{~h}$.

In contrast to the previous scenario, if the solar multiple increases to 2.4 and the size of the TES is equivalent to $6 \mathrm{~h}$, the electricity generation profile is as shown in Figure 11. In this scenario, it is observed that electricity is generated even after the sunset, increasing the annual electric production to $59.69 \mathrm{GWh}$, about $158.21 \%$ of increase when compared with a configuration without TES. In addition, the annual capacity factor also increases, reaching $56.5 \%$. 


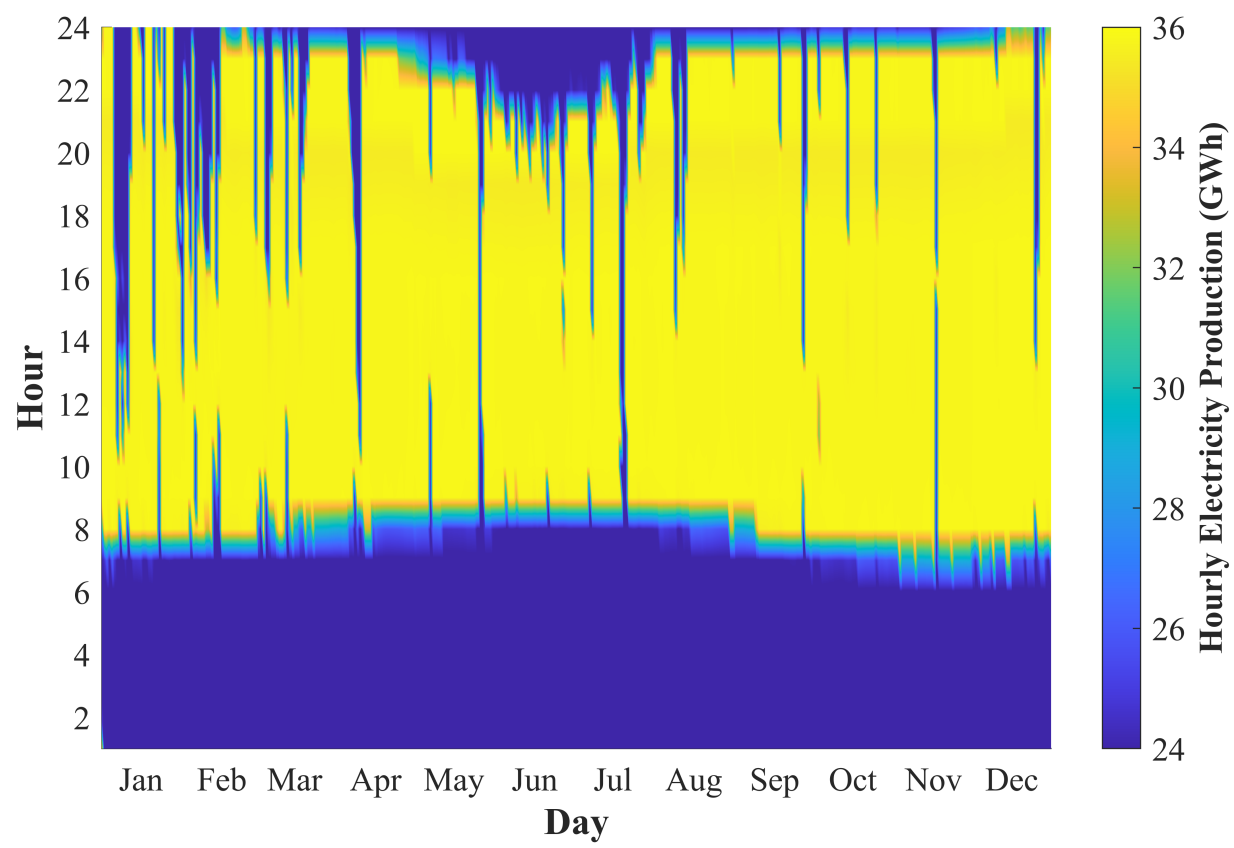

Figure 11. Electricity production profile for configuration strategy $\mathrm{CH} 02-60$, considering $\mathrm{SM}=1.6$ and TES $=6 \mathrm{~h}$.

Due to the differences observed in electricity production, a parametric analysis was carried out aiming to assess the effects of the solar multiple and the size of the TES on the electricity production. From this analysis, it is observed that the electricity generation of the hybrid solar geothermal scheme in the CH01-30, CH01-40, CH02-50, and CH02-60 scenarios is highly dependent on the solar multiple and TES hours, as is shown in Figures 10 and 11. The results obtained by the scenario $\mathrm{CH02-60}$ was taken as an example; however, similar effects were observed in for other integration scenarios. The results shown in Figure 12, depict that scaling both subsystems (solar field and TES) induces a significant increase in electricity generation. However, the effect is only achieved if the scaling is enforced in both subsystems, as pointed out by several authors in designing CSP systems $[25,38]$.

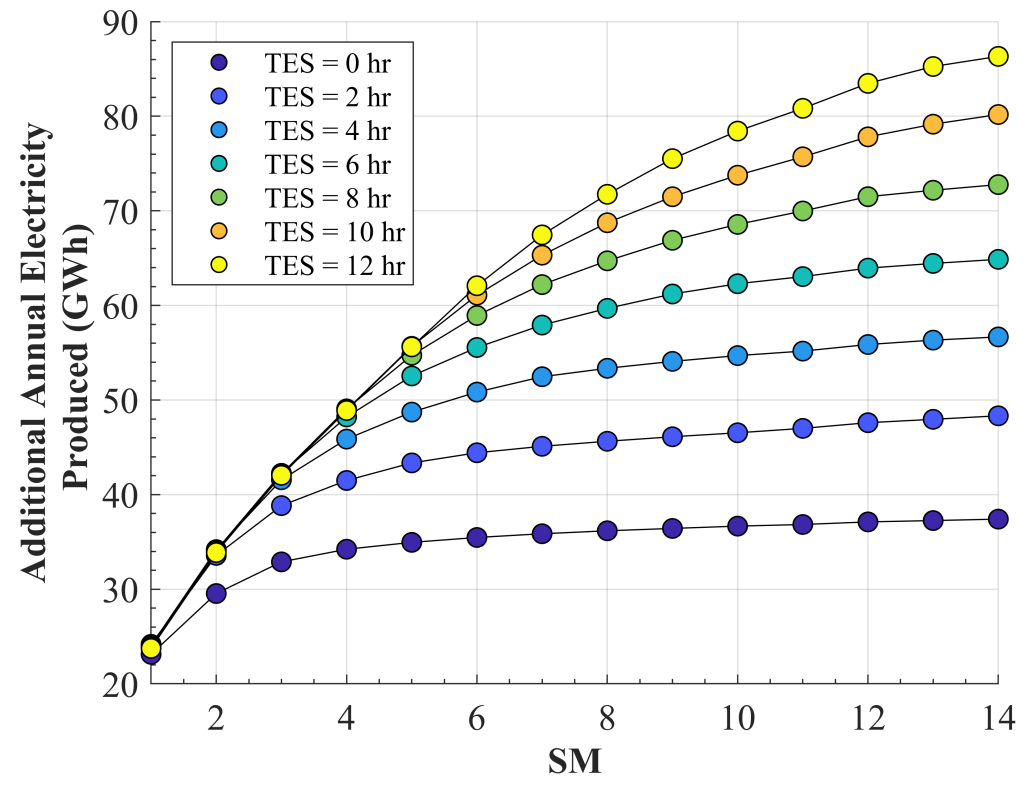

Figure 12. Annual electricity production for $\mathrm{CH} 02-60$ strategy case, according to changes in solar multiple and TES hours. 
Regarding the capacity factor developed by steam power block, a similar behavior is observed. The results are shown in Figure 13, describing the results of the parametric analysis carried out, where the solar multiple and size of the TES were varied. Figure 13 shows that the effect associated with the scale of the solar thermal plant on the capacity factor is significant. The minimum value achieved is $18 \%$ for a solar multiple equal to 1 and disregarding the presence of a TES. This value is nearly to the reference value reported in [2]. In contrast, the maximum value for the capacity factor $(71 \%)$ is observed for a solar multiple of 3 and $12 \mathrm{~h}$ of TES.

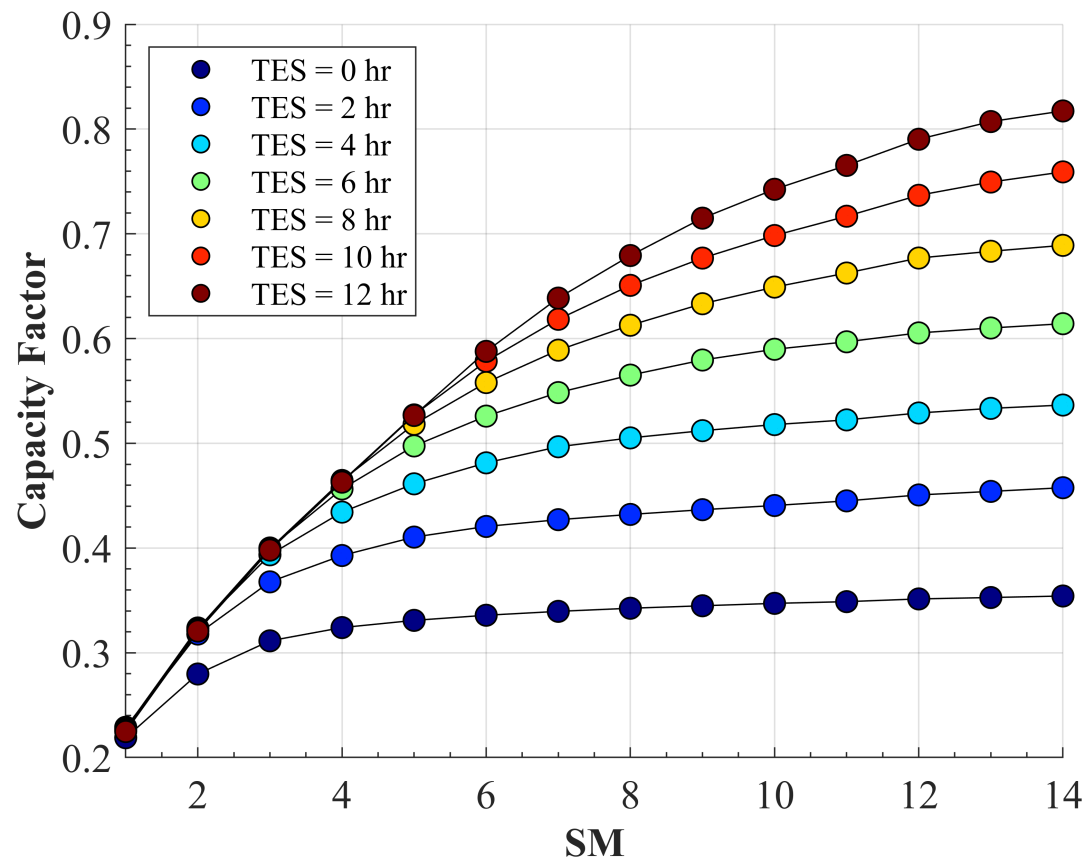

Figure 13. Annual capacity factor for $\mathrm{CH} 02-60$ strategy case, according to changes in solar multiple and TES hours.

It is important to note that as the thermal capacity of the solar field is constraint, the annual production and the capacity factor are independent of the thermal oil nominal temperature. This effect occurs because the model assumes that the amount of oil in the TES is adjusted to admit the solar input. Thus, the effect in terms of energy flow is negligible, but it is significant in terms of economic figures. Such an effect was confirmed by analyzing the scenarios evaluated herein, where it was found that less than $1 \%$ of differences between the inlet and outlet temperatures of thermal oil. However, for the LCOE analysis, it large changes were observed when thermal oil operating temperatures were varied.

\section{Levelized Cost of Electricity}

The economic analysis was based on quantifying the LCOE for each of the 4620 integration scenarios, considering a wide range of values for the solar plant thermal capacity, solar multiple, TES hours and nominal operational temperatures of the thermal oil. The results unveil that small heat exchangers derived the lowest values of LCOE. Figure 14 show LCOE values obtained by the integration of different sizes of TES systems and solar multiples, for the $\mathrm{CH} 01-30, \mathrm{CH} 01-40 \mathrm{CH} 02-50$ and $\mathrm{CH02-60}$ configurations. The figure shows the existence of an optimum LCOE for each configuration, associated to a combination of solar multiple and TES size. However, the four configurations reached an optimum LCOE value for a solar multiple close to 2.6 and $12 \mathrm{~h}$ of TES. The lower LCOE values were 81.22, 80.70, 80.05 and 80.14 USD/MWh, for a solar thermal input of 30, 40, 50 and $60 \mathrm{MW}$, respectively. 

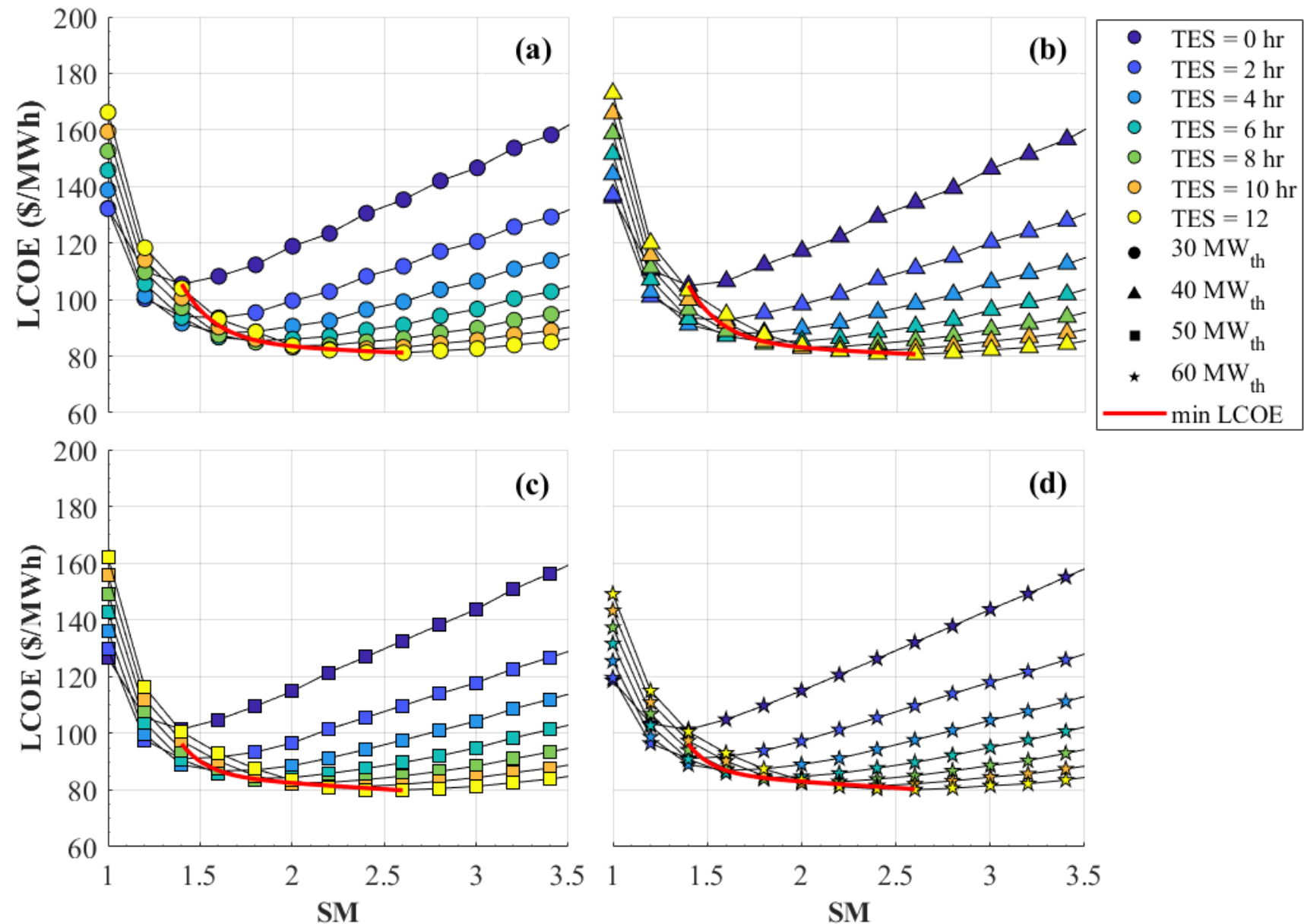

Figure 14. LCOE varying solar multiples and thermal energy storage hours, considering a solar thermal input of $30(\mathbf{a}), 40(\mathbf{b}), 50(\mathbf{c})$, and 60 (d) MW.

Comparing these values with the LCOE observed for a stand-alone geothermal power plant of $20 \mathrm{MW}$, which has a LCOE of $90 \mathrm{USD} / \mathrm{MWh}$ according to [40], there are several configurations that could improve the LCOE thanks to the hybridization, where $\mathrm{CH} 02-50$ reached the lower LCOE values, reducing about $9.95 \%$ with respect to the geothermal stand-alone scenario. Finally, Figure 15 summarizes the configurations in terms of the SM and TES capacity, which minimize the LCOE values for each solar thermal input considered $(30,40,50$, and $60 \mathrm{MW})$. For solar thermal inputs of 30 and $40 \mathrm{MW}$, the LCOE reaches values below $90 \mathrm{USD} / \mathrm{MWh}$ when the solar multiple is equal to or larger than 1.7, and lower than 2.6. Analogously, for the configurations with 50 and $60 \mathrm{MW}$ the minimum LCOE values are also below $90 \mathrm{USD} / \mathrm{MWh}$ when the solar multiple value ranges from 1.51 to 2.6. 


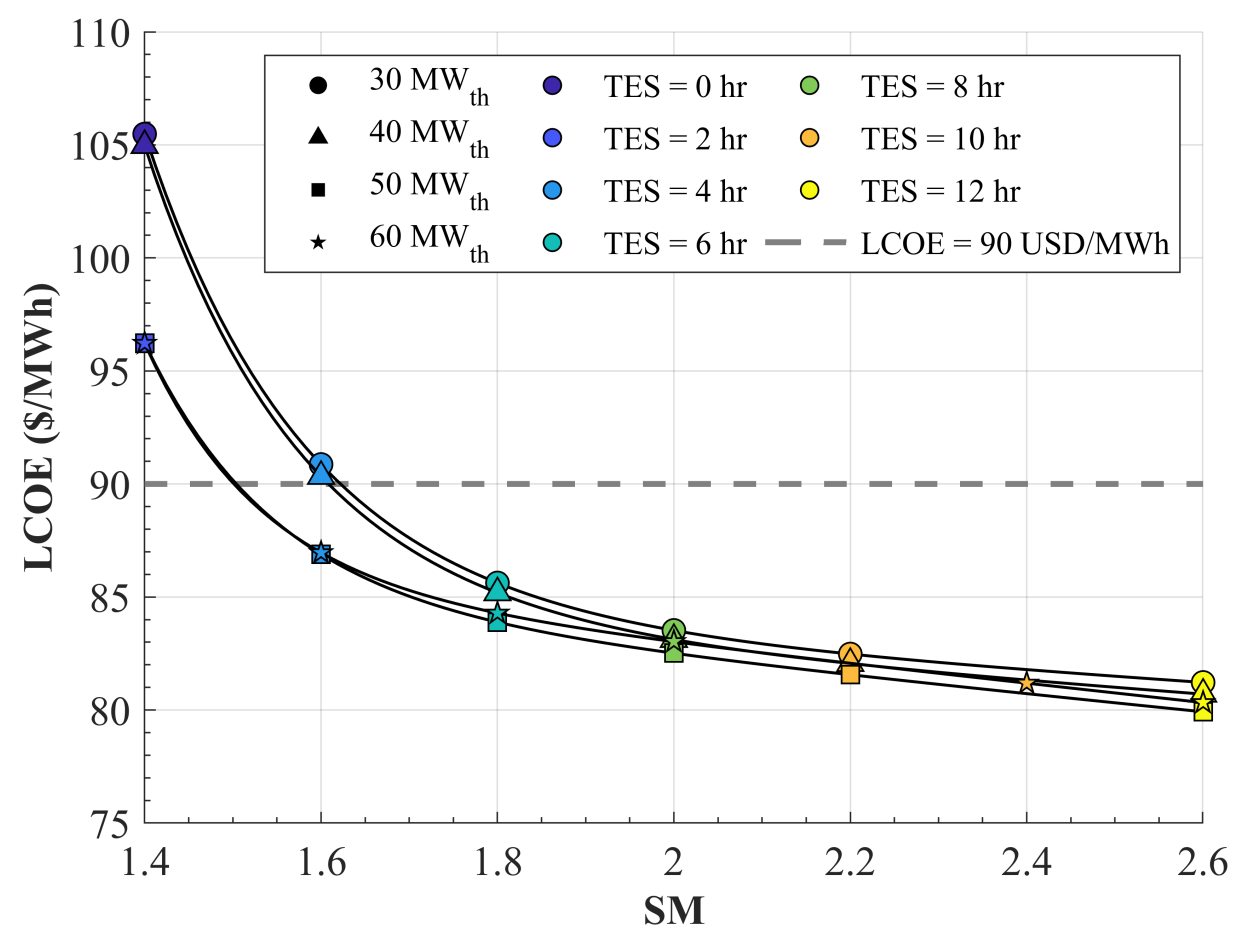

Figure 15. Minimum LCOE values for solar thermal input of 30, 40, 50, and $60 \mathrm{MW}$.

\section{Conclusions}

The analysis of the hybridization of solar and geothermal systems was carried out by simulating the yield of a PTC solar field coupled to a binary cycle with equivalent features as in the Cerro Pabellón geothermal plant. Novel hybrid schemes were analyzed, aiming to assess the integration between both subsystems, considering the location meteorological characteristics and environmental constraints. The introduction of such constraints enhances the analysis carried out in previous studies about hybrid solar and geothermal plants, by including restrictions associated with the actual operation conditions in a geothermal system. The proposed integration schemes consider the implementation of a new power block, ensuring to keep constant the operation conditions of the ORC, avoiding silica precipitation events and the reinjection of brines at equivalent temperatures. Furthermore, different solar thermal capacities, TES hours, solar multiple, and nominal operational temperatures were analyzed, configuring 4620 integration scenarios.

The simulations were carried out in EES and SAM software, allowing to assess the operation of the hybrid schemes in steady and transient states. As for those simulations, a solar field of $30 \mathrm{MW}$ is able to increase the electricity generation in $5.768 \mathrm{MW}$, while a solar field of $60 \mathrm{MW}$ increases in $11.75 \mathrm{MW}$, rising the plant's capacity to $36 \mathrm{MW}$. regarding the thermal efficiency of the hybrid solar geothermal schemes, low changes were observed associated with the hybridization, this low effect is due to the operating constraints imposed by the silica precipitation risk, and by the restriction of preserving the original operating temperatures of the ORC, which are associated to environmental and social requirements. Those restrictions affect the exergy efficiency, where low values of efficiency were scoped, between $38 \%$ and $40 \%$.

In the exergy analysis, the highest exergy destruction occurs at the heat exchanger devices, specifically in IC101 and IC102, where brine preheating and partial evaporation are carried out, which is a crucial factor for the value of nominal operational temperature of thermal oil. Indeed, the lowest exergy destruction rates correspond to the hotter temperature in the solar field $\left(370^{\circ} \mathrm{C}\right)$ and the return temperature to solar field $\left(200^{\circ} \mathrm{C}\right)$. However, heat exchanger devices with greater exergy efficiency are also more expensive, compared with heat exchangers with lower exergy efficiency. 
In terms of the annual electricity production estimated for the scenarios analyzed herein, the most influential parameters are the size of the solar field (solar multiple) and the size of the TES system (TES hours), where the hybridization may increase from $24.17 \mathrm{GWh}$ (solar multiple equal 1 and $2 \mathrm{~h}$ of TES) to 86.33 GWh (considering the solar multiple of 3.6 and $12 \mathrm{~h}$ of TES) annual electricity production. Those rating parameters also present an impact on the capacity factor of the solar plant, ranging from $18 \%$, when solar multiple is 1 and no TES is considered, to 71\% considering a solar multiple of 3 and $12 \mathrm{~h}$ of TES. Thus, the capacity factor is close to the reference values for the conventional power plants, offering high competitiveness as optimal increases in solar multiple and TES hours are evaluated.

Regarding the values of the LCOE, the optimal values were reached when the additional capacity installed is about $11.75 \mathrm{MW}$, where the solar multiple is 2.8 and $12 \mathrm{~h}$ of TES is considered. Such configuration achieves an LCOE of 81.19 USD/MWh, which represents a reduction of $9.8 \%$ regarding a stand alone geothermal plant (about $90 \mathrm{USD} / \mathrm{MWh}$ in a $20 \mathrm{MW}$ geothermal plant). However, the LCOE can increase significantly for other configurations of solar multiple and TES sizes. The lowest LCOE values achieved in the present study could increase the competitiveness of geothermal plants in terms of high generation, high capacity factor, high reliability, low variability, and in terms of economic performance.

In future studies, the authors propose considering the integration of a PV plant, which could operate with the solar thermal plant evaluated in this work. Such a configuration could help to enhance the electricity generation from solar and geothermal sources, as implemented in the Stillwater solar geothermal plant (USA). Combining those technologies, the electricity generation could increase significantly, while operational costs may decrease, reducing LCOE levels. Consequentially, the integration of solar heat into a geothermal plant, such as Cerro Pabellón, could configure a competitive system for delivering clean, secure and reliable electricity.

Author Contributions: Conceptualization, Y.T.-M. and J.M.C.; methodology, Y.T.-M., R.E. and J.M.C.; formal analysis, Y.T.-M. and C.S.-L.; investigation, Y.T.-M. and J.M.C.; resources, R.E. and D.M.; writing-original draft preparation, Y.T.-M. and J.M.C.; writing-review and editing, R.E., C.S.-L. and D.M.; visualization, Y.T.-M.; supervision, J.M.C. and D.M.; project administration, R.E. and J.M.C.; funding acquisition, R.E., J.M.C. and D.M. All authors have read and agreed to the published version of the manuscript.

Funding: This research was funded by the projects ANID/FONDAP/15110019 "Solar Energy Research Center"-SERC-Chile, ANID/FONDAP/15200001 Centro de Excelencia en Geotermia de los Andes, ANID/FONDECYT/1191705 and ANID/FONDECYT/1201337.

Institutional Review Board Statement: Not applicable.

Informed Consent Statement: Not applicable.

Data Availability Statement: Not applicable.

Acknowledgments: The authors wish to acknowledge the support from different parties that led to the completion of this work. In a first place the authors would like to thank ENEL Chile S.A. for sharing the basic information about operating conditions of Cerro Pabellón geothermal plant. In addition, the authors acknowledge the coordination support by G. Quiñones.

Conflicts of Interest: The authors declare no conflict of interest. 


\section{Abbreviations}

The following abbreviations are used in this manuscript:

CSP Concentrated Solar Power

EES Engineering Equation Solver

DNI Direct Normal Irradiance

GHI Global Horizontal Irradiance

HTF Heat Transfer Fluid

LCOE Levelized Cost of Energy

ORC Organic Rankine Cycle

PTC Parabolic Trough Collector

SAM System Advisor Model

TES Thermal Energy Storage

TMY Typical Meteorological Year

\section{Nomenclature}

$A_{t}$

C

$\mathrm{C}_{r}$

$h$

$I_{0}$

in

NTU

$\dot{Q}$

$S$

$S$

$S_{\text {sat }}$

T

$U A$

$\dot{W}$

$\dot{X}$

Greek Symbols

$\Delta T_{\text {LMTD }}$

$\eta_{e x}$

$\eta_{t h}$

$\eta_{T, d}$

$\eta_{T, \mathrm{~s}}$

$\psi$

Subscripts

$c$

dest

el

$g$

$g b$

geo

$h$

in

out

sf

$T$

th

operation and maintenance costs (O\&M)

heat capacitance

heat capacitance ratio

enthalpy

initial investment

mass flow rate

number of heat transfer units

heat transfer rate

specific entropy

silica concentration

silica solubility in pure water

temperature

global heat transfer coefficient

Power

exergy transfer rate

heat exchanger effectiveness

logarithmic mean temperature difference

exergy efficiency

thermal efficiency

efficiency in dry expansion process

isentropic efficiency

specific exergy

cold side

destruction

electricity

generator

geothermal brine

geothermal

hot side

inlet

outlet

solar field

turbine

thermal 


\section{Appendix A}

Table A1. Aperture area under different configurations for solar multiple.

\begin{tabular}{cccccc}
\hline & \multicolumn{3}{c}{ Thermal Capacity (MW) } & \multirow{2}{*}{ Solar Multiple } \\
& $\mathbf{3 0}$ & $\mathbf{4 0}$ & $\mathbf{5 0}$ & $\mathbf{6 0}$ & \multirow{2}{*}{1.0} \\
& 39.24 & 52.32 & 62.13 & 75.21 & 1.2 \\
& 45.78 & 62.13 & 75.21 & 91.569 & 1.4 \\
& 52.32 & 71.94 & 88.29 & 104.64 & 1.6 \\
& 62.13 & 81.75 & 101.37 & 120.99 & 1.8 \\
& 68.67 & 91.56 & 114.45 & 134.07 & 2.0 \\
& 75.21 & 101.37 & 124.26 & 150.42 & 2.2 \\
& 85.02 & 111.18 & 137.34 & 166.77 & 2.4 \\
& 91.56 & 120.99 & 150.42 & 179.85 & 2.6 \\
& 98.1 & 130.8 & 163.5 & 196.2 & 3.0 \\
\hline
\end{tabular}

Table A2. TES capacity considered for the scenarios analyzed.

\begin{tabular}{cccccccccc}
\hline & \multicolumn{1}{c}{ Storage Size (h) } & \multicolumn{3}{c}{ Thermal Capacity } \\
& $\mathbf{0}$ & $\mathbf{2}$ & $\mathbf{4}$ & $\mathbf{6}$ & $\mathbf{8}$ & $\mathbf{1 0}$ & $\mathbf{1 2}$ & (MW) \\
\hline & 0 & 6 & 120 & 180 & 240 & 300 & 360 & 30 \\
Thermal Energy & 0 & 80 & 160 & 240 & 320 & 400 & 480 & 40 \\
Storage Capacity (MWh) & 0 & 100 & 200 & 300 & 400 & 500 & 600 & 50 \\
& 0 & 120 & 240 & 360 & 480 & 600 & 720 & 60 \\
\hline
\end{tabular}

Table A3. Heat exchanger area considered for the scenarios analyzed.

\begin{tabular}{cccccc}
\hline & \multicolumn{3}{c}{ Thermal Capacity $(\mathbf{M W})$} & Nominal \\
& $\mathbf{3 0}$ & $\mathbf{4 0}$ & $\mathbf{5 0}$ & $\mathbf{6 0}$ & Temperature $\left({ }^{\circ} \mathbf{C}\right)$ \\
\hline 1.078 & 1.438 & 1.741 & 2.046 & Th $=390, T c=200$ \\
984 & 1313 & 1586 & 1862 & Th $=390, T c=210$ \\
& 912 & 1216 & 1468 & 1721 & Th $=390, T c=220$ \\
& 853 & 1137 & 1372 & 1608 & Th $=390, T c=230$ \\
& 805 & 1073 & 1293 & 1515 & Th $=390, T c=240$ \\
& 1116 & 1488 & 1802 & 2118 & Th $=380, T c=200$ \\
Heat Exchanger Area $\left(\mathrm{m}^{2}\right)$ & 1018 & 1356 & 1639 & 1924 & Th $=380, T c=210$ \\
& 941 & 1255 & 1515 & 1776 & Th $=380, T c=220$ \\
& 880 & 1173 & 1415 & 1658 & Th $=380, T c=230$ \\
& 830 & 1105 & 1332 & 1560 & $T h=380, T c=240$ \\
& 1156 & 1543 & 1867 & 2195 & $T h=370, T c=200$ \\
& 1053 & 1404 & 1696 & 1991 & $T h=370, T c=210$ \\
& 973 & 1297 & 1566 & 1835 & Th $=370, T c=220$ \\
& 909 & 1211 & 1461 & 1712 & $T h=370, T c=230$ \\
& 856 & 1140 & 1374 & 1609 & $T h=370, T c=240$ \\
\hline
\end{tabular}

\section{References}

1. REN21. Renewables 2020 Global Status Report. In Renewable Energy Policy Network for the 21st Century Secretariat; Technical Report; Paris, France, 2021.

2. IRENA. Renewable Power Generation Costs in 2019; Technical Report; International Renewable Energy Agency: Abu Dhabi, United Arab Emirates, 2020.

3. Li, K.; Liu, C.; Jiang, S.; Chen, Y. Review on hybrid geothermal and solar power systems. J. Clean. Prod. 2020, $250,119481$. [CrossRef] 
4. Tiwari, G.N.; Sahota, L. Advanced Solar-Distillation Systems: Basic Principles, Thermal Modeling, and Its Application; Springer: Singapore, 2017.

5. Cardemil, J.M.; Cortés, F.; Díaz, A.; Escobar, R. Thermodynamic evaluation of solar-geothermal hybrid power plants in northern Chile. Energy Convers. Manag. 2016, 123, 348-361. [CrossRef]

6. Chandrasekharam, D.; Ranjith Pathegama, G. $\mathrm{CO}_{2}$ emissions from renewables: Solar pv, hydrothermal and EGS sources. Geomech. Geophys. Geo-Energy Geo-Resour. 2019, 6, 13. [CrossRef]

7. Li, K.; Bian, H.; Liu, C.; Zhang, D.; Yang, Y. Comparison of geothermal with solar and wind power generation systems. Renew. Sustain. Energy Rev. 2015, 42, 1464-1474. [CrossRef]

8. Lentz, Á.; Almanza, R. Solar-geothermal hybrid system. Appl. Therm. Eng. 2006, 26, 1537-1544. [CrossRef]

9. Lentz, Á.; Almanza, R. Parabolic troughs to increase the geothermal wells flow enthalpy. Sol. Energy 2006, 80, 1290-1295. [CrossRef]

10. Handal, S.; Alvarenga, Y.; Recinos, M. Geothermal Steam Production by Solar Energy. Geotherm. Resour. Counc. Trans. 2007, 31, 503-510.

11. Alvarenga, Y.; Handal, S.; La Geo, M.R. Solar steam booster in the Ahuachapán Geothermal Field. Geotherm. Resour. Counc. Trans. 2008, 32, 395-400.

12. Greenhut, A.D. Modeling and Analysis of Hybrid Geothermal-Solar Thermal Energy Conversion Systems. Master's Thesis, Massachusetts Institute of Technology, Cambridge, MA, USA, 2009.

13. Greenhut, A.D.; Tester, J.W.; Dipippo, R.; Field, R.; Love, C.; Nichols, K.; Augustine, C.; Batini, F.; Price, B.; Gigliucci, G.; et al. Solar-Geothermal Hybrid Cycle Analysis for Low Enthalpy Solar and Geothermal Resources. In Proceedings of the World Geothermal Congress, Bali, Indonesia, 25-30 April 2010; pp. 25-29.

14. Astolfi, M.; Xodo, L.; Romano, M.C.; Macchi, E. Technical and economical analysis of a solar-geothermal hybrid plant based on an Organic Rankine Cycle. Geothermics 2011, 40, 58-68. [CrossRef]

15. Boghossian, J.G. Dual-Temperature Kalina Cycle for Geothermal-Solar Hybrid Power Systems. Ph.D. Thesis, Massachusetts Institute of Technology, Cambridge, MA, USA, 2011.

16. Manente, G.; Field, R.; DiPippo, R.; Tester, J.W.; Paci, M.; Rossi, N. Hybrid Solar-Geothermal Power Generation to Increase the Energy Production From a Binary Geothermal Plant. In Proceedings of the ASME 2011 International Mechanical Engineering Congress and Exposition, Denver, CO, USA, 11-17 November 2011; pp. 109-119.

17. Zhou, C.; Doroodchi, E.; Munro, I.; Moghtaderi, B. A Feasibility Study on Hybrid Solar-Geothermal Power Generation. In New Zealand Geothermal Workshop 2011 Proceedings; University of Auckland: Auckland, New Zealand 2011; p. 7.

18. Zhou, C.; Doroodchi, E.; Moghtaderi, B. An in-depth assessment of hybrid solar-geothermal power generation. Energy Convers. Manag. 2013, 74, 88-101. [CrossRef]

19. Zhou, C. Hybridisation of solar and geothermal energy in both subcritical and supercritical Organic Rankine Cycles. Energy Convers. Manag. 2014, 81, 72-82. [CrossRef]

20. Ghasemi, H.; Sheu, E.; Tizzanini, A.; Paci, M.; Mitsos, A. Hybrid solar-geothermal power generation: Optimal retrofitting. Appl. Energy 2014, 131, 158-170. [CrossRef]

21. Ayub, M.; Mitsos, A.; Ghasemi, H. Thermo-economic analysis of a hybrid solar-binary geothermal power plant. Energy 2015, 87, 326-335. [CrossRef]

22. Calise, F.; d'Accadia, M.D.; Macaluso, A.; Piacentino, A.; Vanoli, L. Exergetic and exergoeconomic analysis of a novel hybrid solar-geothermal polygeneration system producing energy and water. Energy Convers. Manag. 2016, 115, 200-220. [CrossRef]

23. Jiang, P.X.; Zhang, F.Z.; Xu, R.N. Thermodynamic analysis of a solar-enhanced geothermal hybrid power plant using $\mathrm{CO}_{2}$ as working fluid. Appl. Therm. Eng. 2017, 116, 463-472. [CrossRef]

24. Bonyadi, N.; Johnson, E.; Baker, D. Technoeconomic and exergy analysis of a solar geothermal hybrid electric power plant using a novel combined cycle. Energy Convers. Manag. 2018, 156, 542-554. [CrossRef]

25. McTigue, J.D.; Castro, J.; Mungas, G.; Kramer, N.; King, J.; Turchi, C.; Zhu, G. Hybridizing a geothermal power plant with concentrating solar power and thermal storage to increase power generation and dispatchability. Appl. Energy 2018, 228, 1837-1852. [CrossRef]

26. Ciani Bassetti, M.; Consoli, D.; Manente, G.; Lazzaretto, A. Design and off-design models of a hybrid geothermal-solar power plant enhanced by a thermal storage. Renew. Energy 2018, 128, 460-472. [CrossRef]

27. Tranamil, Y. EvaluacióN TermodinÁMica Y EconÓMica de la IntegraciÓN de un Campo Solar de ConcentraciÓN a una Central GeotÉRmica Emplazada en el Norte de Chile. Master's Thesis, University of Chile, Santiago, Chile, 2019.

28. Procesi, M. Geothermal Potential Evaluation for Northern Chile and Suggestions for New Energy Plans. Energies 2014, 7, 5444-5459. [CrossRef]

29. GDM. Study on the Environmental Impacts of the "Cerro Pabellon" Geothermal Project; Technical Report; GDM Geothermics; Elsevier Ltd.: Glasgow, UK, 2010.

30. GDM. Study on the Environmental Impacts of the Expansion of the "Cerro Pabellon" Geothermal Project; Technical Report; GDM Geothermics; Elsevier Ltd.: Glasgow, UK, 2016.

31. GeoModel-Solar. In SolarGIS climData @; SolarGis: Bratislava, Slovakia, 2019.

32. F-Chart Software. Engineering Equation Solver (EES 2021). Available online: https://www.fchartsoftware.com/ees/ (accessed on 25 January 2022). 
33. National Renewable Energy Laboratory. System Advisor Model (Version SAM 2020.11.29). Available online: https://sam.nrel. gov/ (accessed on 25 January 2022).

34. Dincer, I.; Rosen, M. Exergy, 2nd ed.; Elsevier: Amsterdam, The Netherlands, 2013; p. 570.

35. Nellis, G.; Klein, S. Heat Transfer; Cambridge University Press: New York, NY, USA, 2009.

36. DiPippo, R. Geothermal Power Plants: Principles, Applications, Case Studies and Environmental Impact, 4th ed.; Elsevier: Amsterdam, The Netherlands, 2015; p. 762.

37. Utami, W.S.; Herdianita, N.R.; Atmaja, R.W. The Effect of Temperature and pH on the Formation of Silica Scaling of Dieng Geothermal Field. In Proceedings of the Thirty-Ninth Workshop on Geothermal Reservoir Engineering, Stanford, CA, USA, 24-26 February 2014; p. 6.

38. Starke, A. AnáLise ExergoeconôMica de uma Central de ConcentraçãO Solar de Coletores Cilindro-ParabóLicos Hibridizada Com CombustíVel FóSsil E Sistema Fotovoltaico. Ph.D. Thesis, Federal University of Santa Catarina, Florianópolis, Brazil, 2019.

39. Bensenouci, A.; Medjelled, A. Thermodynamic and Efficiency Analysis of Solar Steam Power Plant Cycle. Int. J. Renew. Energy Res. (IJRER) 2016, 6, 1556-1564.

40. MINENERGIA. Energia 2050-National Energy Policy; Technical Report; Energy Ministry of Chile: Santiago, Chile, 2020. 